\title{
HIGH TEMPERATURE CORROSION STUDY INTERIM REPORT FOR THE PERIOD NOVEMBER 1958 THROUGH MAY 1959
}

By

C. $\mathrm{F} . \mathrm{Hat}$

E. J. Barber

H. A. Bernhardi

Karl E. Rapp

July 28, 1959

Oak Ridge Gaseous Diffusion Plant

Oak Ridge, Tennessee

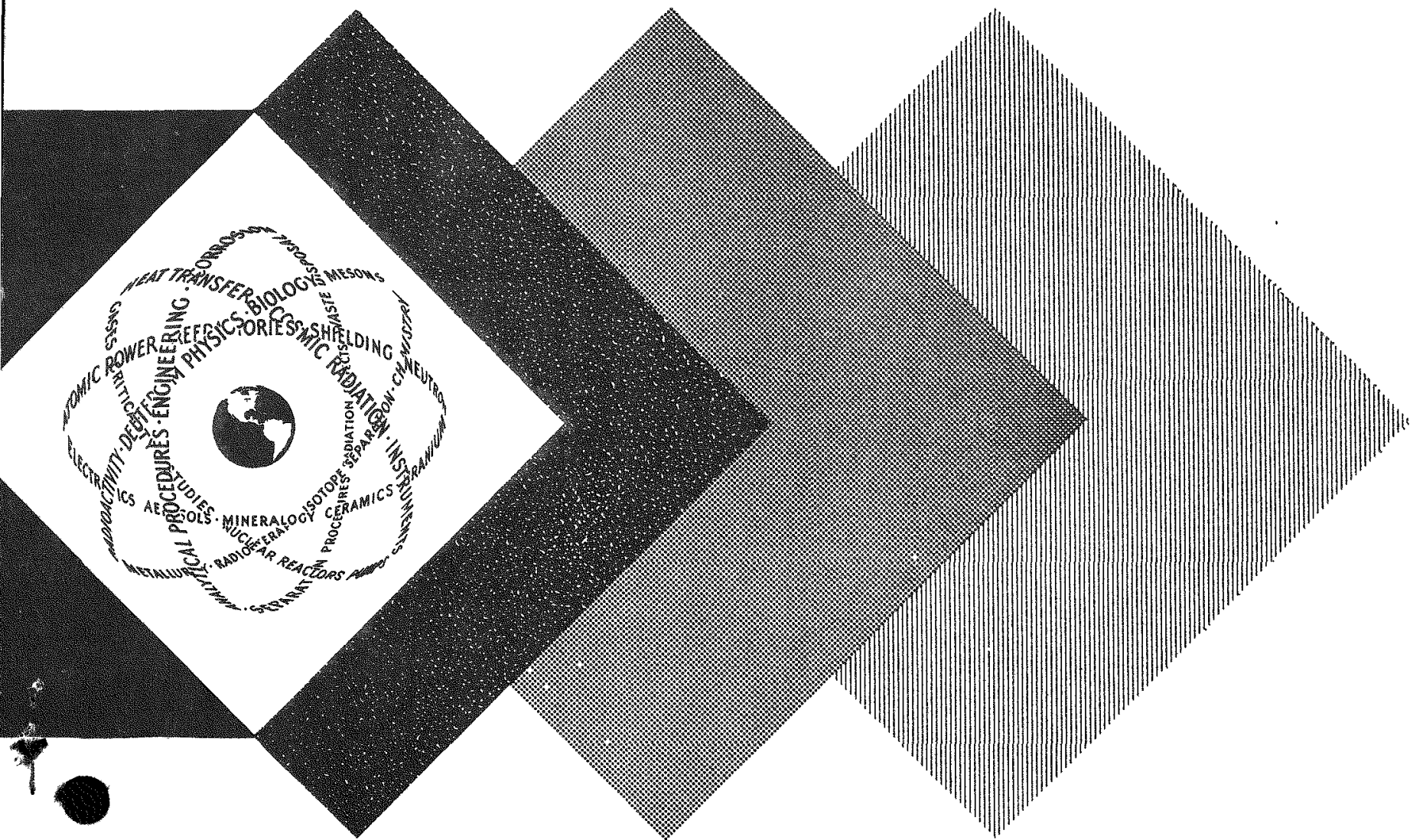


Date Declassified: October 22, 1959.

This is a corrected version of an earlier report prepared as $\mathrm{KL}-498$.

\section{LEGAL NOTICE}

This report was prepared as an account of Government aponsored work. Neither the United States, nor the Commisston, nor any person scting on behalf of the Commission:

A. Makes any warranty or representation, expressed or Implled, with respect to the accuracy, completeness, or usefulness of the inforration contained in this report, or that the use of any information, spparatus, method, or process disclosed in this report may not infringe privately owned rights; or

B. Assumes any liabilities with respect to the use of, or for damages resulting from the use of any information, apparatus, method, or process disclosed in this report.

As used in the above. "person acting on behalf of the Commission" includes any employee or contractor of the Comminsion, or employee of such contractor, to the extent that such employee or contractor of the Commission, or employee of such contractor prepares, disseminates, or provides access to, any information pursuant to his employment or contract with the Commission, or his employment with such contractor.

This report has been reproduced directly from the best available copy.

Printed in USA. Price $\$ 1.25$. Avallable from the Office of Technical Services, Department of Commerce, Washington 25, D. C.

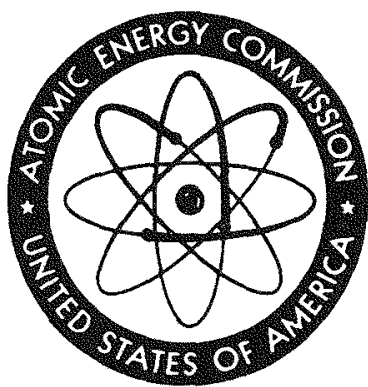




\title{
AECD -4292
}

HIGE TEMPERATURE CORROSION STUDY

INTERIM REPORT FOR THE PERIOD NOVEMBER 1958 THROUGH MAY 1959

\author{
C. F. Hale, E. J. Barber, H. A. Bernhardt, \\ and Karl E. Rapp
}

\author{
Chemical Development Department \\ Technical Division \\ D. M. Lang, Superintendent
}

\begin{abstract}
This document contains information of a preliminary nature and was prepared primarily for internal use. It is subject to revision and/or correction, and does not represent a final report.
\end{abstract}

Date of Issue: July 28, 1959

UNION CARBIDE NUCLEAR COMPANY

Division of Union Carbide Corporation

Oak Ridge Gaseous Diffusion Plant

Oak Ridge, Tennessee 
Title: HIGH TEMPERATURE CORROSION STUDY

INTERIM REPORT FOR THE PERIOD

NOVEMBER 1958 THROUGH MAX 1959

Authors: C.F. Hale, E.J. Barber,

H. A. Bernhardt, and Karl E. Rapp

\section{A B S T R A C T}

Samples of grade A Monel and grade A nickel were subjected statically in a single reactor to an undiluted atmosphere of gaseous fluorine at pressures up to one atmosphere absolute and temperatures up to $1500^{\circ} \mathrm{F}$. The rate of consumption of fluorine on the mixed Monel and nickel samples was followed by a pressure-drop technique at 1100 and $1300^{\circ} \mathrm{F}$, but was found to be too rapid to be followed accurately at $1500^{\circ} \mathrm{F}$. The grade $\mathrm{A}$ Monel was conservatively estimated to have consumed at least 40 times as much fluorine as the grade A nickel during the entire period of this exploratory investigation. Consequently, Monel metal was eliminated from further consideration as a material of construction for equipment exposed to fluorine at temperatures higher than $1300^{\circ} \mathrm{F}$.

Nickel was found to form a continuous, adherent fluoride film with an undiluted fluorine atmosphere at temperatures up to $1800^{\circ} \mathrm{F}$. Examination with the electron microscope showed the nickel fluoride film to be a polycrystalline array about one crystal layer thick and to have few flaws in the individual crystals which would permit direct access of the fluorine to the nickel surface underneath. Thus the primary mechanism of attack through the film appears to be diffusion along the crystal boundaries. A definite degree of stabilization was attained between nickel and fluorine at these elevated temperatures; as the nickel fluoride film thickened, more resistance to attack was obtained. The reaction rate between nickel coated with fluoride films several hundred thousand angstrom units in thickness and undiluted fluorine appeared to be directly pressure dependent at 1100 and $1300^{\circ} \mathrm{F}$. and considerably less pressure dependent at $1500^{\circ} \mathrm{F}$. A growth in the crystalline size of both the nickel and nickel fluoride was observed as the reaction temperature was increased from 1500 to $1800^{\circ} \mathrm{F}$. Considerable intergranular attack of the metallic nickel was experienced at temperatures of 1500 and $1800^{\circ} \mathrm{F}$; the depth of penetration due to attack along the grain boundaries of the metal was estimated to be 5 to 8 times the average attack as calculated from scale formation.

Samples of fused $\alpha$-alumina, $\alpha$ alumina-magnesium oxide spinel, and $\alpha=a l u m i n a-$ nickel oxide-nickel cermet were exposed to undiluted fluorine at one atmosphere absolute pressure at temperatures of 1340 and $1500^{\circ} \mathrm{F}$. By visual observations the samples retained their original shape and showed no evidence of a nonuniform attack. Conversion of the sample surfaces to the respective 
metal fluorides was ascextained by X-ray diffraction patterns of the films. From the weight gain of the $\alpha-a$ lumina during the $1340^{\circ} \mathrm{F}$. fluorine exposure a rather arbitrary comparison based on the average depths of penetration indicated that the $\alpha$ alumina is as good as the nickel in the region of $1300^{\circ} \mathrm{F}$, and is worthy of further consideration.

Grade A nickel samples coated with nickel fluoride films of 37,000 and $74,000 \mathrm{~A}$. , respectively, were exposed to an absolute pressure of gaseous uranium hexafluoride of $12 \mathrm{~cm}$. of mercury at temperatures of 1500 and $1800^{\circ} \mathrm{F}$. The initial uranium hexafluoride consumption rates at 1500 and $1800^{\circ} \mathrm{F}$. were of the order of 700 and $800 \mathrm{mg} . \mathrm{U} / \mathrm{sq}$. ft./day, respectively. Both nickel fluoride and uranium tetrafluoride corrosion products have appreciable vapor pressures at these test temperatures and were observed to migrate to the cooler portions of the reactor by vapor phase transfer. The average penetration of the nickel by the uranium hexafluoride at $1500^{\circ} \mathrm{F}$. calculated from the average nickel fluoride scale formation appeared to be about $1 / 3$ of that experienced with fluorine at $1300^{\circ} \mathrm{F}$. and a comparable pressure. The grade A nickel exposed to gaseous uranium hexafluoride at these elevated temperatures exhibited a grain boundary type attack on the nickel surfaces beneath the fluoride scale quite similar to that experienced in the exposures to fluorine.

Lobservations subsequent to the study reported above indicate that after passage of an initial period during which a relatively low corrosion rate in uranium hexafluoride at $1800^{\circ} \mathrm{F}$. is experienced, nickel is attacked at an accelerated rate with the resultant deposition of large quantities of uranium tetrafluoride. Thus the use of nickel to contain uranium hexafluoride or fluorine at $1800^{\circ} \mathrm{F}$. is not promising due to the volatility and instability of the nickel fluoride, the intergranular attack of the metal, and the proximity to the melting point of nickel, $\left.2647^{\circ} \mathrm{F}.\right]$ 
TABLE OF CONIENTS

Part I. The Resistance of Monel and Nickel to an Undiluted Atmosphere of Fluorine at Elevated Temperatures $\ldots-m \infty-\infty$

A. Exploratory Study with Nickel and Monel $-\infty-\infty-\infty-\infty$

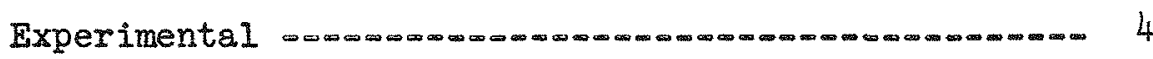

Apparatus and Materials $m=0$

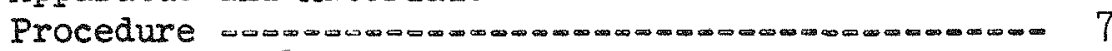

Results and Discussion m-

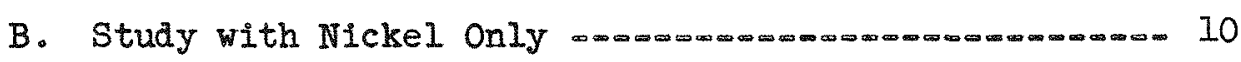

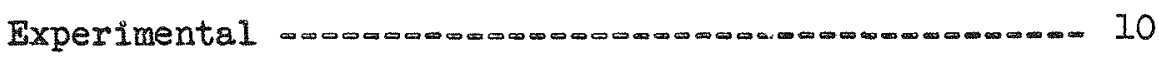

Results and DIscussion $m-\infty \infty m-\infty$

Part II. Exposure of Refractory Oxides and a Cermet to

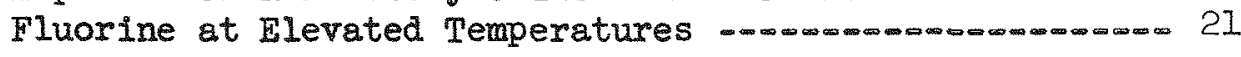

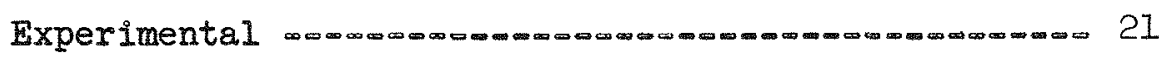

Apparatus and Materials

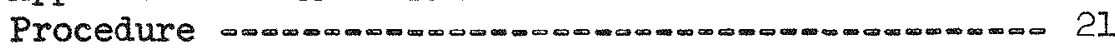

Results and Discussion $-\infty-\infty-\infty-\infty-\infty-\infty-\infty-\infty-\infty-\infty-\infty-\infty-\infty-\infty-\infty 23$

Part III. The Exposure of Nickel Coated with a Heavy Film of Nickel Fluoride to Uranium Hexafluoride at

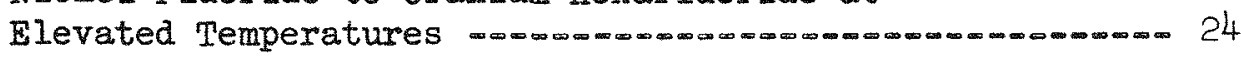

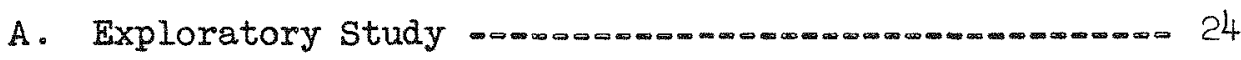

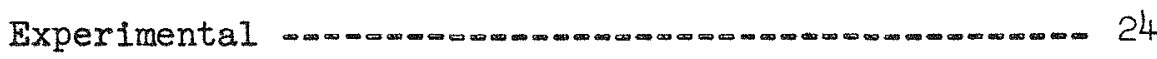

Apparatus and Materials $-\infty-\infty-\infty-\infty-\infty-\infty-\infty-\infty-\infty-\infty-\infty-\infty) 24$

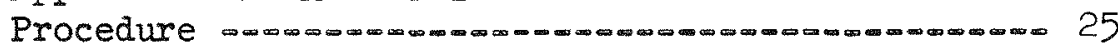

Results and Discussion $-\infty-\infty-\infty-\infty-\infty-\infty-\infty-\infty-\infty-\infty-\infty-\infty-\infty-25$

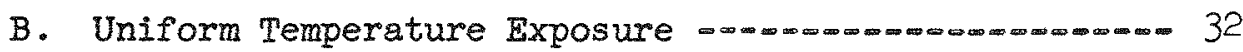

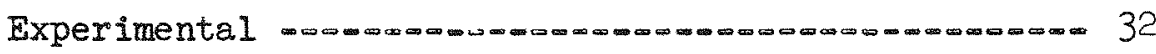

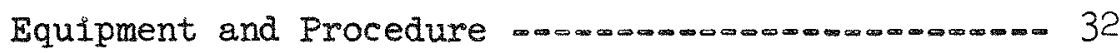

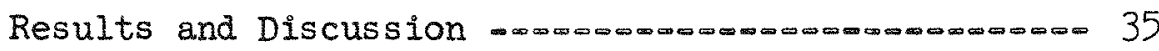

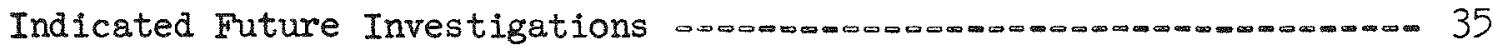

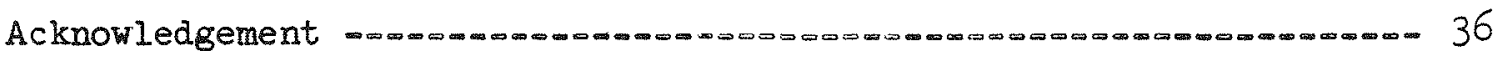

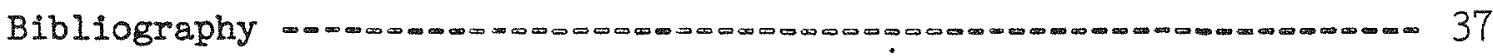

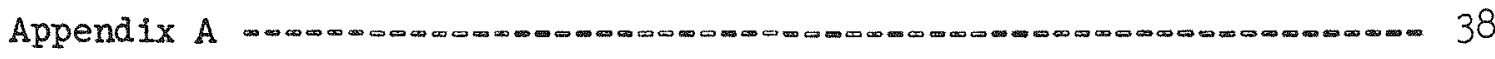


HIGH TEMPERATURE CORROSION STUDY

INTERIM REPORT FOR THE PER IOD NOVEMBER 1958 THROUGH MAY 1959

Because the homogeneous gaseous uranium hexafluoride reactor concept appears to offer some real advantages in reactor technology, a study of the behavior of materials of construction in withstanding the corrosive action of uranium hexafluoride and fluorine at the necessarily high temperatures and pressures required for efficient power production was undertaken. To passivate metals against the further corrosive action of fluorine and uranium hexafluoride, a metal fluoride coating which is both adherent and continuous must be formed. Further, this continuous, adherent film should be impervious to the corrosive gas; and of course, to remain continuous, adherent, and impervious, the metal fluoride must be nonvolatile. Other considerations for nearly complete passivation of metals are that there be little or no migration of the metal atoms out through the fluoride film and that the metal itself exhibit no appreciable vapor pressure at the operating temperature.

The investigations encompassed by this interim report involve the resistance of the metals, Monel and nickel, the refractory oxides, $\alpha-a l u m i n a$ and magnesium oxide $\alpha-\alpha$ alumina spinel, and the cermet, nickel-nickel oxide- $\alpha-a l u m i n a$, to fluorine at elevated temperatures and the resistance of nickel coated with a heavy nickel fluoride film to uranium hexafluoride at elevated temperatures. Since the apparatus and procedures are somewhat lifferent in each of these investigations, they will be presented separately.

PART I. THE RESISTANCE OF MONEL AND NICKEL TO AN UNDILUTED ATMOSPHERE OF FLUORINE AT ELEVATED TEMPERATURES

From rather extensive data on the corrosion of metals by fluorine and uranium hexafluoride at considerably lower temperatures, nickel and Monel were chosen as the metals most promising for high temperature application. other metals that might at first appear promising, for the most part, either form volatile fluorides or do not form impervious, adherent fluoride films.

\section{A. Exploratory Study with Nickel and Monel}

\section{Experimental}

Apparatus and Materials. The reactor assembly and the manifold employed in the investigation of the corrosion resistance of Monel and nickel to fluorine at elevated temperatures are shown in figures 1 and 2 , respectively. The reactor, which was about $5=1 / 2$ inches long, was constructed from 3 -inch grade A nickel pipe with a 0.216 inch wall. The ends were made of 0.250 inch grade $A$ nickel plate, and final assembly was effected by all mickel welding. The reactor was surrounded by a $3 / 4$ inch thick Inconel shield to provide better temperature uniformity and to prevent excessive atmospheric oxidation on the outside of the reactor. To reduce this atmospheric oxida tion further, the shield was connected with a source of nitrogen or helium 


\section{34กำ

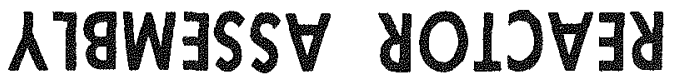

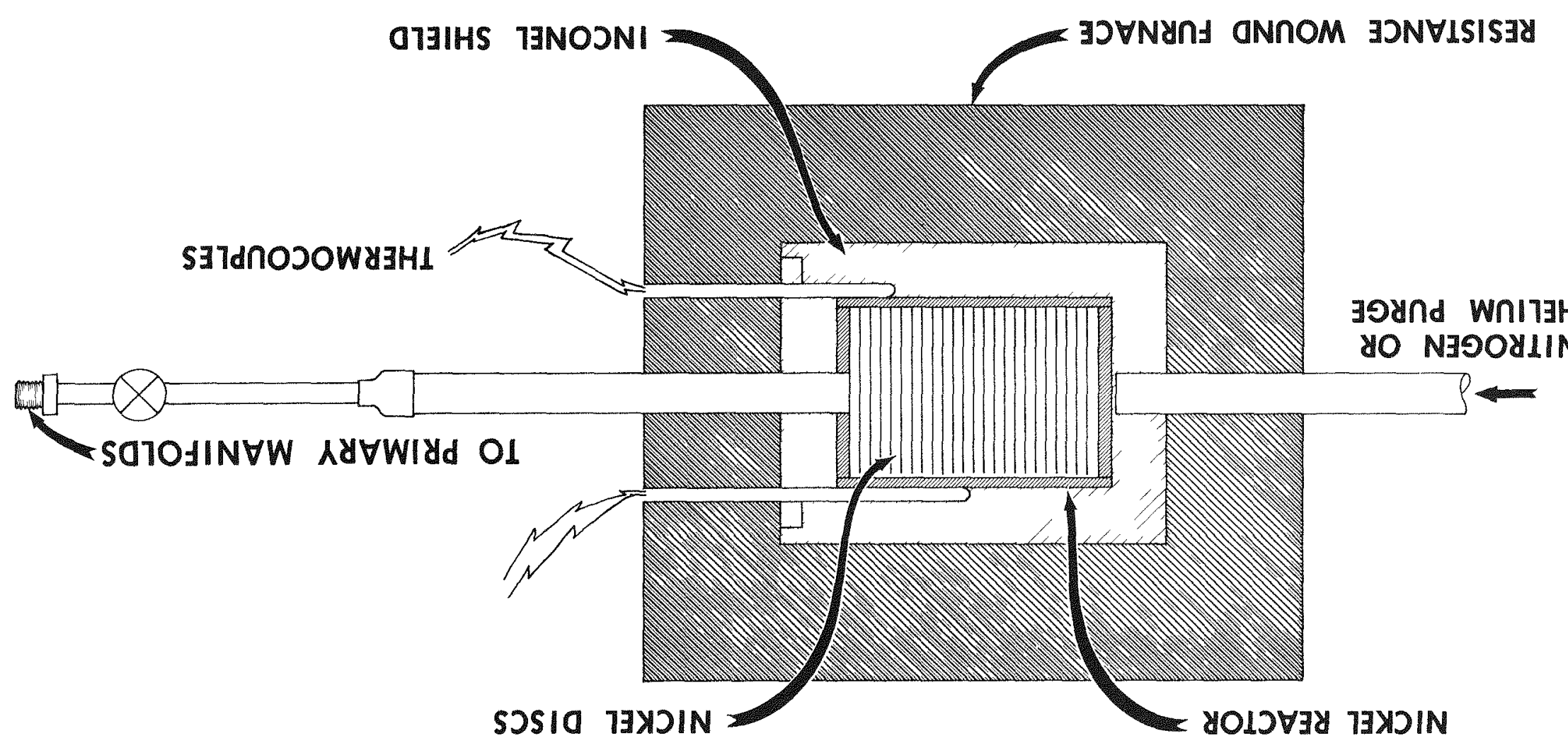




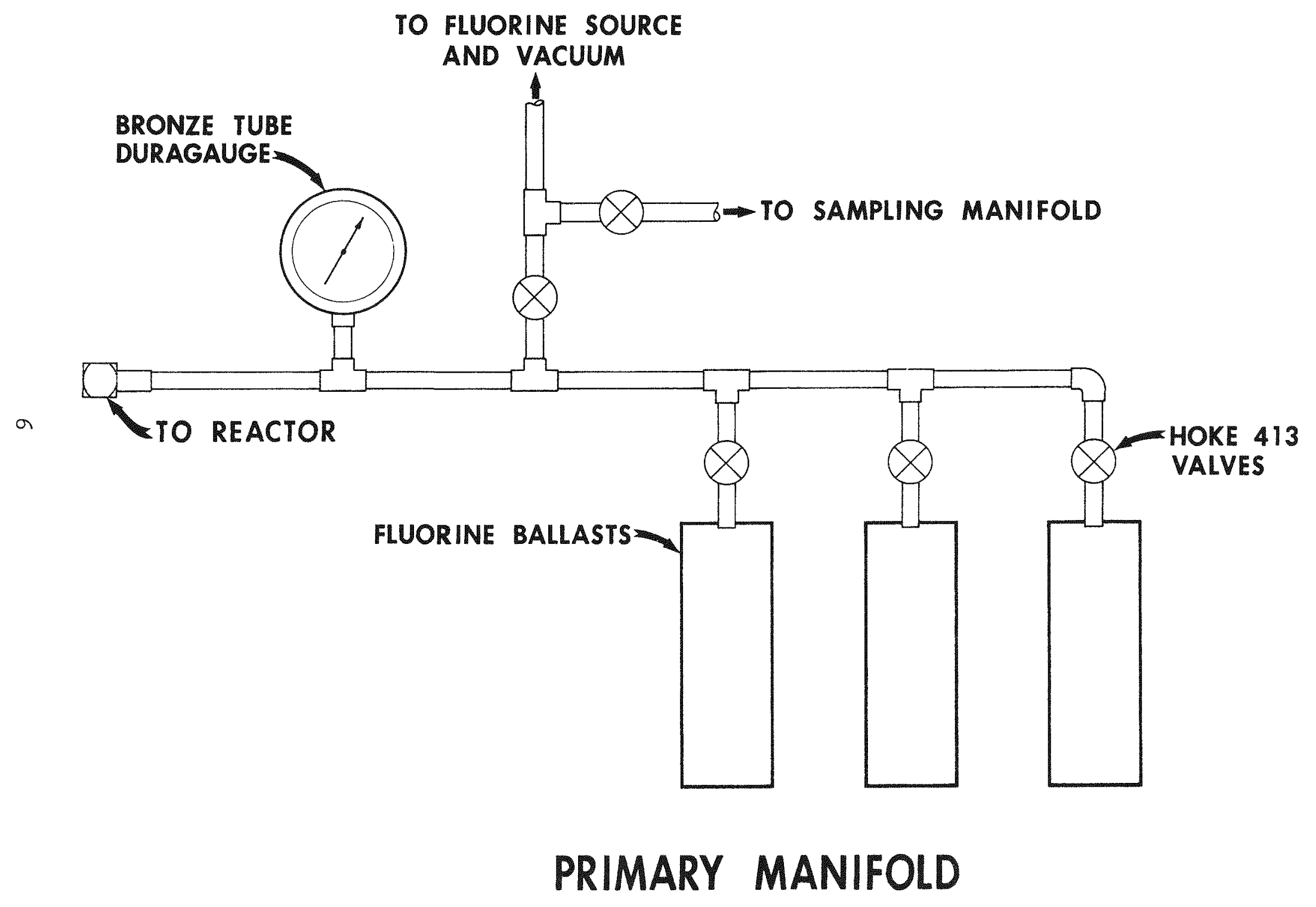

FIGURE 2 
which could be used to purge between the shield and reactor. The reactor was heated by a 12-inch Hevi-Duty resistance-wound tube furnace, 5 inches in diameter; and the temperature at the control point was maintained within $\pm 8^{\circ} \mathrm{F}$. by means of a Brown controlling potentiometer. The temperature of the reactor was measured by two chromel-alumel thermocouples located between the reactor and shield, one midway of the length on top, used in conjunction with the controlling potentiometer, and the other one quarter of the length of the reactor on the bottom. These thermocouples indicated the temperature gradient within the reactor was less than $10^{\circ} \mathrm{F}$.

The reactor was connected to a manifold, figure 2, which was constructed from nickel tubing. The Hoke 413 valves had Monel bodies, Inconel diaphragms, and stainless steel stems. The pressure gage was a bronze tube Duragauge with a range of 0 to 30 inches vacuum calibrated in $1 / 2$ Inch units. All the valves and the gage had the parts silver soldered together in manufacture. The fluorine ballasts were 3-liter tanks of allnickel welded construction.

The individual components of the assembly were silver soldered together or connected by aluminum-gasketed Dalton couplings. The Monel and nickel samples were discs, $25 \mathrm{mils}$ in thickness and $2-7 / 16$ inches in diameter, which had been punched from grade A sheet material; the nickel was $1 / 2$ hard and the Monel was annealed. The discs were supported in a vertical position equidistant from the sides of the reactor by a slotted rack which had been formed from $1 / 16$-inch grade A nickel sheet.

The nominal composition of grade A nickel is as follows: minimum weight per cent nickel, 99.0; minimum weight per cent nickel and cobalt, 99.5; maximum welght per cent silicon, 0.5 ; carbon, 0.2 ; manganese, 0.5 ; and iron, 0.35. The nominal composition of grade A Monel is as follows: weight per cent nickel, 63.0 to 70.0 ; copper being the remainder with maximum weight per cent impurities of iron, 0.25; manganese, 1.25; carbon, 0.3 ; silicon, 0.5 ; and sulfur, 0.024 . The fluorine used in these investigations was produced at the ORGDP fluorine plant and was subsequently passed. through a sodium fluoride trap to reduce the hydrogen fluoride content. The following mass spectrometer analysis in terms of mole per cent is typical of the fluorine used: fluorine, 96.9; nitrogen, 1.4; oxygen, 1.1; hydrogen fluoride, 0.5 ; and carbon dioxide, 0.1 .

Procedure. The reactor and end-plate along with the rack and sample discs were degreased with Freon-113; the rack was loaded with 12 grade A Monel discs and 12 grade $A$ nickel discs; and then the rack containing the discs was inserted into the reactor with the nickel discs forward toward the fluorine entrance tube. The back end-plate was then Heliarc welded in position, and the reactor was assembled in the furnace and connected to the manifold.

After the system was leak tested, the volumes of the separate components of the ballast and the reactor were calibrated; the system was thoroughly evacuated, and fluorine was admitted to the ballasts from the source supply. Subsequently, fluorine was admitted to the reactor, and the temperature of 
the reactor was raised and maintained at the desired level while the manifold assembly remained at ambient room temperature. Employing the ideal gas laws, the initial fluorine pressure of the expansion was calculated from the respective volumes, temperatures, and pressures involved. The fluorine consumption rate as indicated by the pressure arop on the Duragauge was calculated from the PVT relationships as a function of time. If the fluorine consumption was low, or if an accurate value was desired, only the reactor and the primary manifold, which included the gage and lines connecting the various parts of the assembly, were involved in the pressuredrop measurements; otherwise, when the primary purpose of the run was to increase the thickness of the fluoride film, one or more of the ballast cans were included in the pressure arop system.

At the conclusion of an exposure, the sample was examined visually; chemical analysis for total fluoride was performed on the discs; identification of the corrosion products was made by $X-r a y$ diffraction techniques; the metal was examined metallographically; and the fluoride films were replicated with carbon for electron microscopic examination.

\section{Results and Discussion}

The fluorine consumption rates on the mixed Monel and nickel samples during the first exposure could be measured quite easily by the pressure-drop technique at 1100 and $1300^{\circ} \mathrm{F}$, but were too rapla to be followed accurately at $1500^{\circ} \mathrm{F}$. After several hours exposure to undiluted fluorine at pressures up to 1 atmosphere absolute at each of the temperatures, 1100, 1300, and $1500^{\circ} \mathrm{F}$, the temperature was lowered to $1300^{\circ} \mathrm{F}$. where the fluorine consump tion rate on the sample was followed again for several hours previous to concluding the exposure. The total fluorine exposure times and temperatures are as follows: 8 hours at $1100^{\circ} \mathrm{F}, 24$ hours at $1300^{\circ} \mathrm{F}$, and 4 hours at $1500^{\circ} \mathrm{F}$. It should be noted that the samples were maintained under vacuum at each of these temperatures for many additional hours.

From the fluorine consumed on the mixed Monel and nickel samples during the course of the first investigation, measured both by weight gain of the total sample and the pressure drop, volume, and temperature observations, an over-all average fluoride film about $775,000 \mathrm{~A}$. thick was calculated to have been produced. The nickel fluoride found on the nickel discs by $X$ cray absorption techniques was estimated to have an average thickness of 43,000 A.

From these film measurements and the respective geometric areas exposed, the Monel was estimated to have consumed at least 40 times as much fluorine as the nickel during this investigation. A picture of the reactor, rack, and. discs after exposure is presented in figure 3 . The 12 nickel discs are farther away in the rack and the 12 Monel discs are toward the front; the mixed sample was exposed in the reactor with the nickel discs toward the fluorine admission line seen in the background. The first few Monel discs over which the fluorine passed are considerably more heavily corroded than those at the rear of the reactor and are completely converted to the fluow ride around their perimeter. This indicates that during the $1500^{\circ} \mathrm{F}$. run when the attack rates were immeasurably high that fluorine consumption 


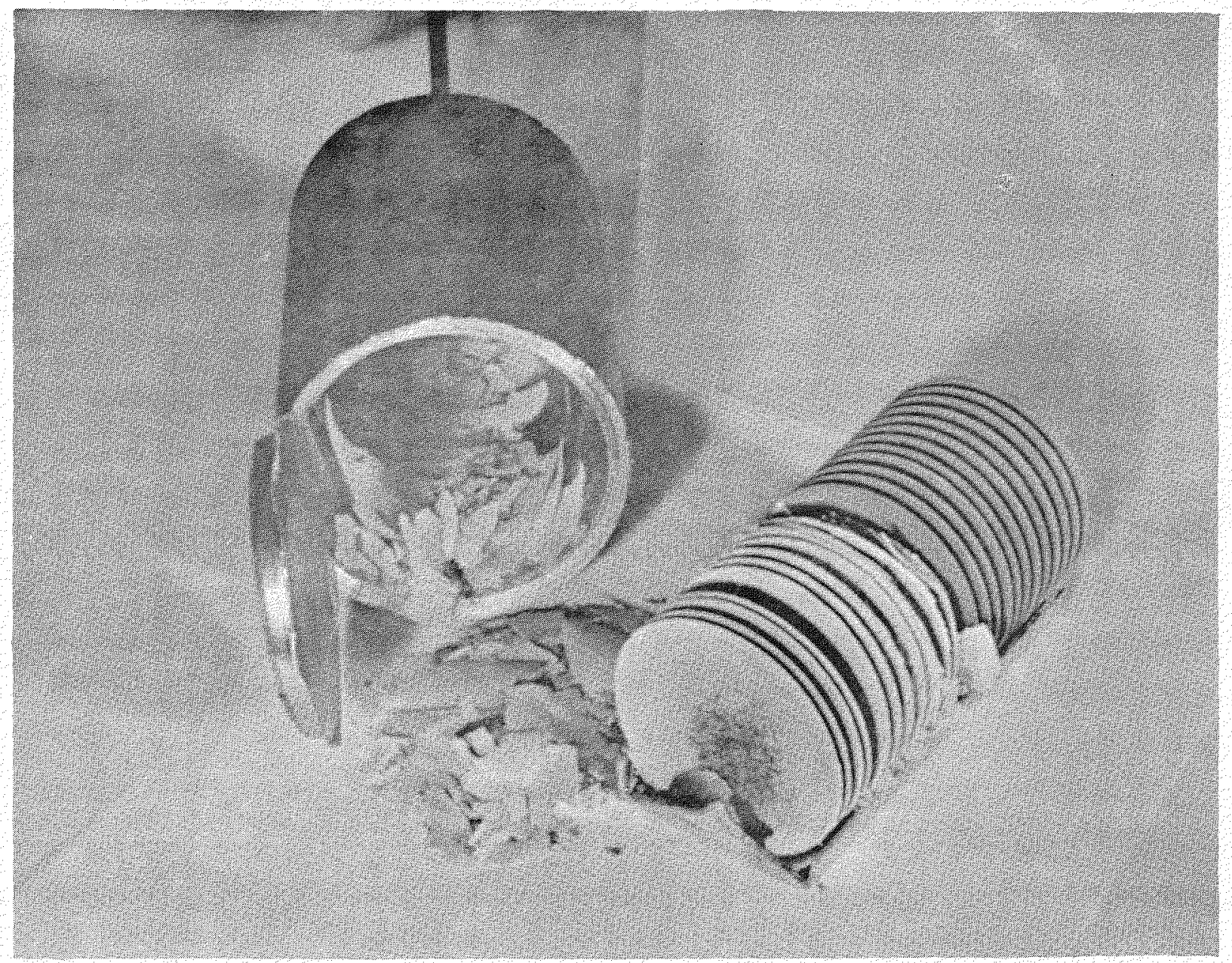

GRADE A NICKEL AND GRADE A MONEL EXPOSED TO FLUORINE AT TEMPERATURES UP TO $1500^{\circ} \mathrm{F}$ 
by the Monel was limited by the prevailing rate of fluorine addition to the reactor so that the amount of fluorine wich contacted the discs at the rear was less than that contacting the first Monel discs. Thus the calculated ratio of the total fluorine consumption by Monel and nickel of about 40 to 1 would appear to be conservative.

Electron micrographs of carbon replicas of the nickel fluoride formed during the first investigation are presented in figure 4. Slightly etched patterns, cavities, and what appear to be superficial flaws are in evidence on the nickel fluoride crystals, but no predominance of cracks or crevices extending to the underlying nickel are seen. The crystal size is in the range of 3 to 4 microns as noted from the scale of figure 4. This is about the same thickness as the total fluoride film found on the discs at the conclusion of the exposure by $\mathrm{X}$-ray absorption measurements. It is, therefore, believed that the nickel fluoride film formed at these elevated temperatures by the reaction of nickel and fluorine, while polycrystalline, is essentlally just one crystal layer in thickness.

In summary, Monel metal was eliminated from further consideration as a material of construction for equipment exposed to fluorine at temperatures above $1300^{\circ} \mathrm{F}$. Monel may possibly have limited value as a material of construction for fluorine and uranium hexafluoride at temperatures up to about $1300^{\circ} \mathrm{F}$. The appearance of the nickel that had been exposed to fluorine at temperatures up to $1500^{\circ} \mathrm{F}$. Was more encouraging; the fluoride film was continuous, adherent, and appeared from the electron micrographs to have few flaws in the crystals themselves that would permit direct access of the fluorine to the nickel surface underneath.

\section{B. Study with Nickel only}

\section{Experimental}

The second investigation was carried out similarly to the first using only grade A nickel discs in the previously described all-nickel system.

During this investigation the grade A nickel was exposed to undiluted fluorine at pressures up to $I$ atmosphere absolute and temperatures up to $1800^{\circ} \mathrm{F}$. The sample was exposed first at $1100^{\circ} \mathrm{F}$. and then $1300^{\circ} \mathrm{F}$. after which the temperature was lowered to $1100^{\circ} \mathrm{F}$, and the fluorine pressure dependence of the consumption rates was measured. Later, the temperature was increased to $1300^{\circ} \mathrm{F}$. and $1500^{\circ} \mathrm{F}$. with consumption rates determined as a function of fluorine pressure at each temperature. Finally, the sample was exposed to fluorine at $1800^{\circ} \mathrm{F}$. for about 35 hours before termination of the exposure. The total fluorine exposure times and temperatures were as follows: 232 hours at $1100^{\circ} \mathrm{F}, 106$ hours at $1300^{\circ} \mathrm{F}, 19$ hours at $1500^{\circ} \mathrm{F}$. , and 35 hours at $1800^{\circ} \mathrm{F}$. It should be noted, however, that the samples were maintained under vacuum at each of these temperatures several days longer. 


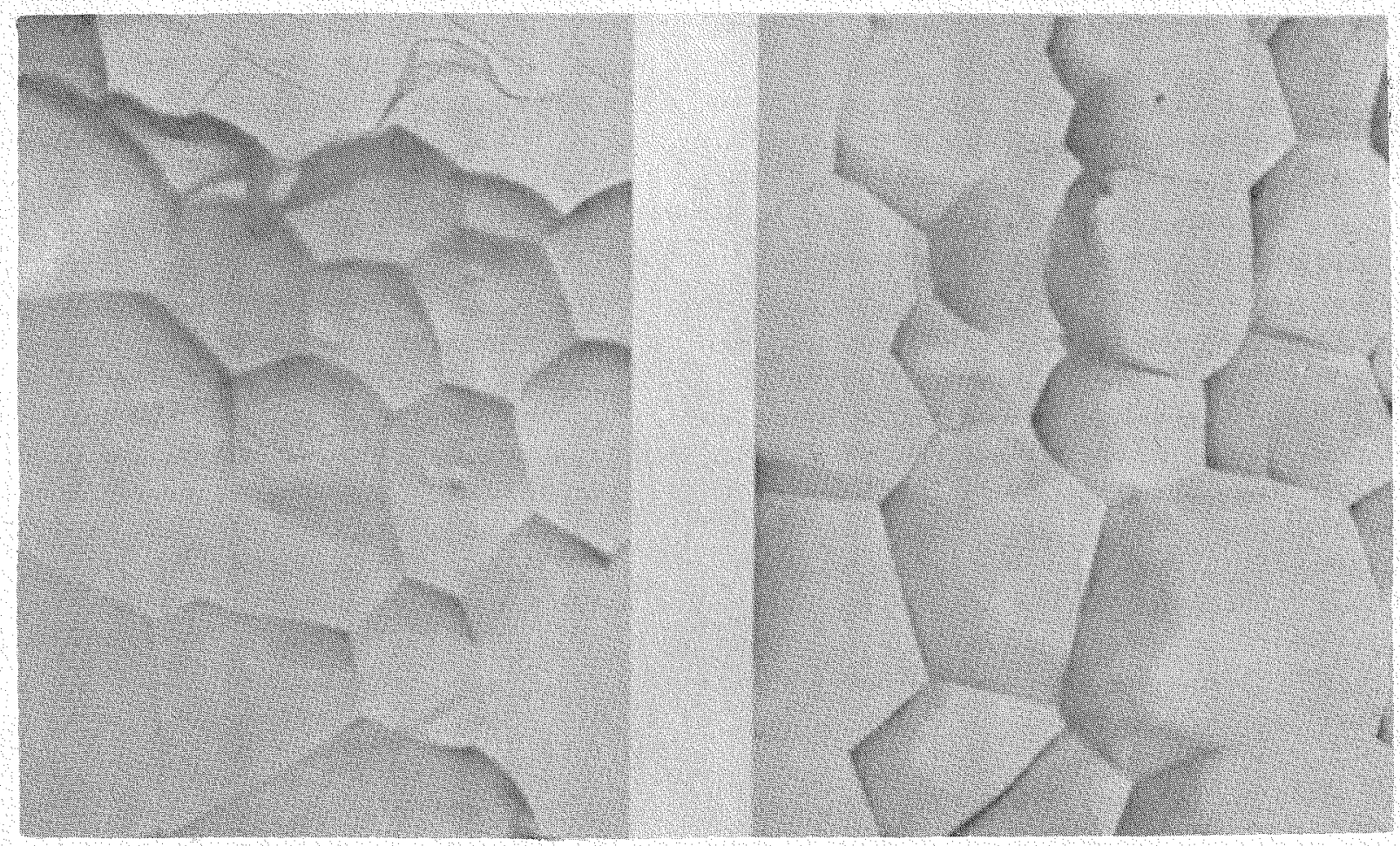

$$
1500^{\circ} \mathrm{F} \text {. }
$$

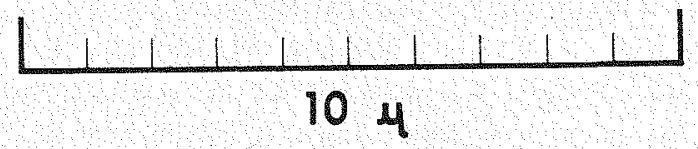

\section{NICKEL FLUORIDE FORMED ON GRADE A NICKEL AT ELEVATED TEMPERATURES \\ FIGURE 4}


Table I presents data showing the variation in average fluorine consumption rates obtained from pressure decay observations over the approximate pressure range of 0.2 to $0.8 \mathrm{~atm}$. absolute at 1100,1300 , and $1500^{\circ} \mathrm{F}$. with nickel fluoride film of varying average thickness; the corresponding varlations in the average rates of nickel fluoride film formation are shown also. The data in parentheses were interpolated at equivalent fluorine pressure from a graph of the pressure dependency of the fluorine consumption rates presented in figure 5. The data in table I show that the rates of fluorine consumption at a given temperature decrease as the fluoride film thickens; thus a definite degree of stabilization is realized.

The variations of the fluorine consumption rates at 1100,1300 , and $1500^{\circ} \mathrm{F}$. with the fluorine pressure are presented in figure 5 in which the logarithm of fluorine consumption rate is shown as a function of the logarithm of the average fluorine pressure. Typical data at 1100,1300 , and $1500^{\circ} \mathrm{F}$. are presented in table II. From observation of the plot of the data in figure 5 and from consideration of the rate equation applicable to the bimolecular reaction of fluorine with nickel presented in Appendix $A$, it becomes apparent that the reaction at 1100 and $1300^{\circ} \mathrm{F}$. Is almost first order with respect to the fluorine pressure; i.e., at 1100 and $1300^{\circ} \mathrm{F}$. the rate of the reaction between nickel coated with a thick film of nickel fluoride (of the order of $2.0 \times 10^{5}$ to $5.4 \times 10^{5} \mathrm{~A}$ ) and fluorine is almost directly proportional to the fluorine pressure.

The consumption rates at 1100 and $1300^{\circ} \mathrm{F}$. are not directly comparable as presented on the graph, viz., the $1300^{\circ} \mathrm{F}$. rates are not just about an order of magnitude greater than the $1100^{\circ} \mathrm{F}$. rates, since at the two given temperatures the logarithm of the pressure is not directly comparable to the logarithm of the concentration. The concentrations at 1100 and $1300^{\circ} \mathrm{F}$. are rather inversely proportional to the absolute temperatures at the same pressures. Although this does not change the slopes of the two plots and thus the order of reaction or pressure dependence, it would increase the $1300^{\circ} \mathrm{F}$. rates about 12 per cent over those presented on the graph. Also, the consumption rates are not directly comparable due to the difference in total nickel fluoride film thickness present during the separate measurements. The rates at $1100^{\circ} \mathrm{F}$. were taken after an average of about $200,000 \mathrm{~A}$. of nickel fluoride had been deposited and those at $1300^{\circ} \mathrm{F}$. after about $540,000 \mathrm{~A}$. of nickel fluoride had been laid down.

The data on the pressure dependence of the fluorine consumption rate at $1500^{\circ} \mathrm{F}$. as presented in table II and figure 5 were taken after an average of $6.3 \times 105 \mathrm{~A}$. of nickel fluoride had been deposited. Surprisingly, the fluorine consumption rates obtained at $1500^{\circ} \mathrm{F}$. were of the same order of magnitude as the rates obtained at $1300^{\circ} \mathrm{F}$, the rates at $1500^{\circ} \mathrm{F}$. being slightly greater at low and slightly lower at high fluorine pressures than the corresponding $1300^{\circ} \mathrm{F}$. rates. Consequently, the $1500^{\circ} \mathrm{F}$. rates are less dependent on the fluorine pressure; i.e., quadrupling the pressure only about doubles the consumption rate instead of quadrupling it as with the $1300^{\circ} \mathrm{F}$. rates. 


\section{FLUORINE ATTACK ON NICKEL AT ELEVATED TEMPERATURES}

TABLE I

\begin{tabular}{|c|c|c|c|}
\hline $\begin{array}{c}\text { TEMPERATURE, } \\
{ }^{\circ} \mathrm{F} .\end{array}$ & $\begin{array}{l}\text { THICKNESS OF } \mathrm{NiF}_{2} \\
\text { AT START OF } \\
\text { MEASUREMENT, } \AA .\end{array}$ & $\begin{array}{l}\mathrm{F}_{2} \text { CONSUMPTION } \\
\text { RATE, } \\
\mathrm{mg} . \mathrm{F}_{2} / \mathrm{sq}^{\mathrm{fft}} \mathrm{a} / \mathrm{hr} \text {. }\end{array}$ & $\begin{array}{l}\text { RATE OF NiF, } \\
\text { DEPOSITION, } \\
\AA . / \mathrm{hr} .\end{array}$ \\
\hline \multirow[t]{4}{*}{1100} & $\begin{array}{l}13,000^{b} \\
20,000\end{array}$ & $\begin{array}{r}158 \\
14\end{array}$ & $\begin{array}{r}9,350 \\
830\end{array}$ \\
\hline & 40,000 & 11 & 650 \\
\hline & 70,000 & 7 & 415 \\
\hline & 73,000 & $\begin{array}{r}7 \\
(53)\end{array}$ & $\begin{array}{l}415 \\
13121\end{array}$ \\
\hline \multirow[t]{4}{*}{1300} & 75,000 & 175 & 10,400 \\
\hline & 131,000 & 108 & 6,390 \\
\hline & 153,000 & 46 & 2,720 \\
\hline & 560,000 & (41) & $(2,450)$ \\
\hline 1500 & 630,000 & 28 & 1,660 \\
\hline
\end{tabular}




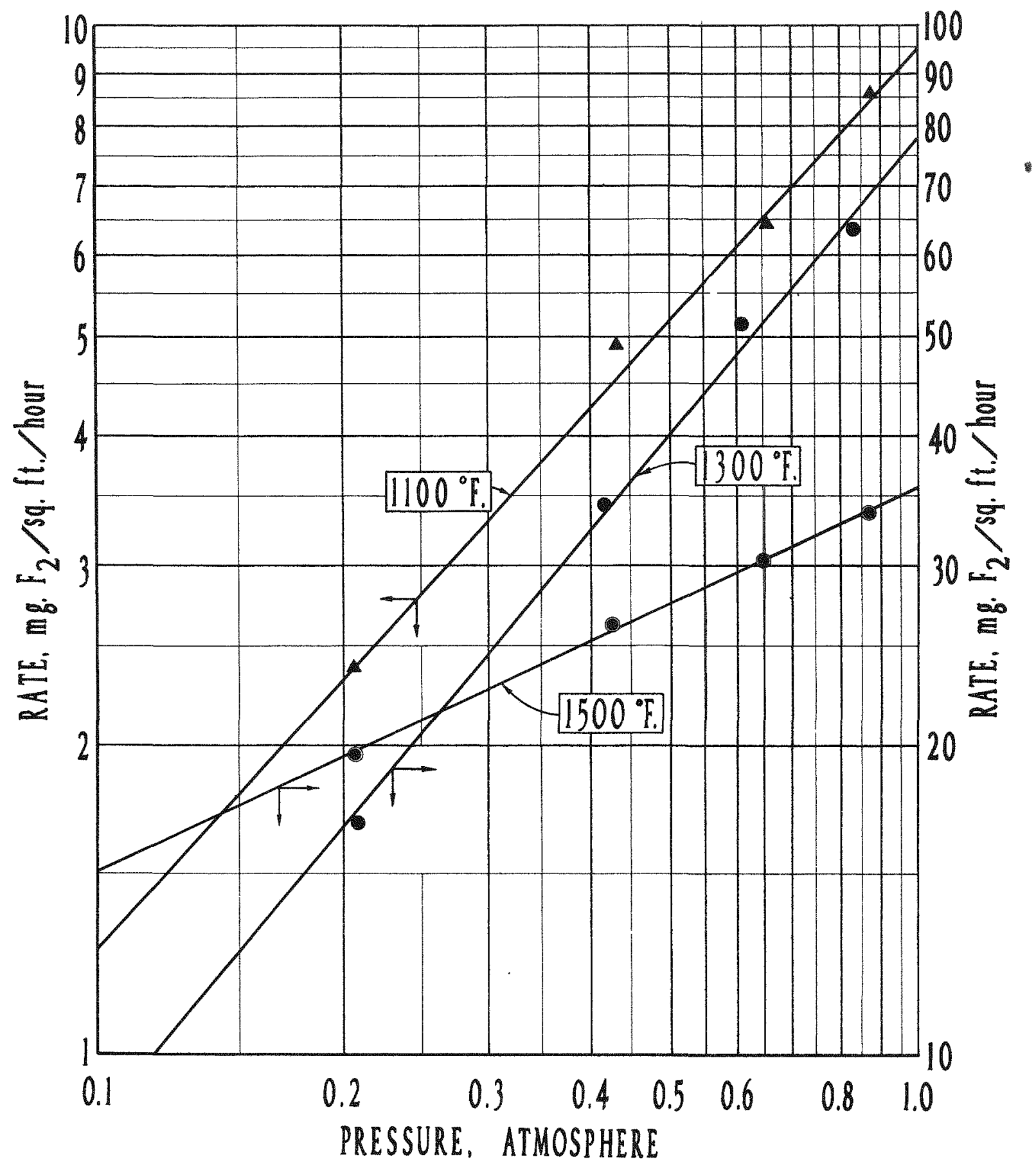

\section{PRESSURE DEPENDENCE OF THE REACTION OF FLUORINE WITH NICKEL AT HIGH TEMPERATURES}

FIGURE 5 
TABLE II

PRESSURE DEPENDENCE OF THE FLUORINE CONSUMPTION RATE

\begin{tabular}{|c|c|c|c|c|}
\hline $\begin{array}{l}\text { Pressure of } \\
\text { System, } \\
\text { atm. } \\
\end{array}$ & $\begin{array}{l}\text { Consumption Rate, } \\
\text { gg. } \mathrm{F}_{2} / \mathrm{sq} . \mathrm{ft} \cdot / \mathrm{hr} \text {. }\end{array}$ & $\begin{array}{c}\text { Nickel Fluoride } \\
\text { Formation Rate, } \\
\text { A./hr. }\end{array}$ & $\begin{array}{c}\text { Nickel Fluoride } \\
\text { Film at Start } \\
\text { of Measurements, } \\
\text { A. } \\
\end{array}$ & $\begin{array}{c}\text { Temperature, } \\
{ }^{\circ} \mathbf{F} \text {. }\end{array}$ \\
\hline 0.21 & 2.4 & 140 & $2.0 \times 10^{5}$ & 1100 \\
\hline 0.43 & 4.9 & 290 & & \\
\hline 0.65 & 6.4 & 380 & & \\
\hline 0.87 & 8.6 & 510 & & \\
\hline 0.21 & 16.7 & 990 & $5.4 \times 10^{5}$ & 1300 \\
\hline 0.41 & 34.2 & 2020 & & \\
\hline 0.62 & 51.2 & 3030 & & \\
\hline 0.83 & 63.7 & 3770 & & \\
\hline 0.21 & 19.7 & 1166 & $6.3 \times 10^{5}$ & 1500 \\
\hline 0.42 & 26.2 & 1551 & & \\
\hline 0.65 & 30.3 & 1794 & & \\
\hline 0.87 & 33.3 & 1971 & & \\
\hline
\end{tabular}


While these results at $1500^{\circ} \mathrm{F}$. were entirely unexpected, metallographic studies provide a plausible explanation for the observed effects. The metallographic studies indicate that recrystallization and extensive grain growth of the metal occurred. Since during recrystallization and rapid growth the mobility of the nickel atoms is considerably greater than the mobility after these processes are completed, the exhibition of similar rates at 1300 and $1500^{\circ} \mathrm{F}$. would be understandable if the $1300^{\circ} \mathrm{F}$. rates were measured during the rapid grain growth period and the $1500^{\circ} \mathrm{F}$. data were obtained when the grain growth process had become quite slow. Furthermore, there are no a priori reasons to expect the same dependence of the rate of reaction on the fluorine pressure for these two conditions since any change in the mobility of the nickel atoms would affect stability of the metal-metal fluoride interface.

The importance of the formation of an adherent, continuous, and impervious fluoride film for successful passivation cannot be overemphasized. Since a film which volatilizes generally will not have these properties, the necessicy for evaluation of the effect of volatility on the protective qualities of a nickel fluoride film at high temperatures is apparent from the vapor pressure of nickel fluoride (2) plotted as an inverse function of temperature in degrees Kelvin, figure 6. Equivalent Fahrenheit temperatures of particular interest are indicated by the reference scale included.

At the conclusion of this investigation, the nickel, remained intact and was visually sound. The nickel fluoride film formed at temperatures up to $1800^{\circ} \mathrm{F}$. was visually observed to be composed of larger crystals than the film formed at temperatures up to $1500^{\circ} \mathrm{F}$; yet the film still appeared to be continuous and adherent. Figure 7 presents a photograph of the grade $A$ nickel discs, rack, and reactor which were exposed to fluorine at temperatures up to $1800^{\circ} \mathrm{F}$; visual comparisons may be made with the nickel and Monel exposed to fluorine up to $1500^{\circ} \mathrm{F}$, figure 3.

From the total weight gain on the discs and their total geometric area, an average nickel fluoride film of $5.3 \times 105 \mathrm{~A}$. was calculated to be present assuming a roughness factor of unity. $X$-ray absorption measurements of the film present on the discs showed that the film was continuous but varied in thickness not only from disc to disc but in different locations on the same disc by as much as a factor of two. The average film thickness computed from the $\mathrm{X}$-ray absorption measurements was $2.2 \times 10^{5} \mathrm{~A}$.

Metallographic examination of the nickel discs exposed at 1500 and $1800^{\circ} \mathrm{F}$. was performed. Photomicrographs of cross sections of the exposed nickel discs along with one of an untreated blank are presented on the left side of figure 12. Some interesting things are obvious from these photomicrographs. First, growth of the nickel crystal at the temperatures of 1500 and $1800^{\circ} \mathrm{F}$. can be observed by comparison with the untreated blank. This is a typical recrystallization which is characteristic of the behavior of metals at temperatures above about 0.4 of the melting temperatures in degrees Kelvin, and is assertedly due to the attempt of the metals to reach a more stable configuration by formation of larger crystals with less total surface area. The temperatures of exposure of the nickel as regards the fraction of the melting temperature in degrees Kelvin are as follows: $1100^{\circ} \mathrm{F} .-0.50,1300^{\circ} \mathrm{F}-0.57,1500^{\circ} \mathrm{F},-0.63$, and $1800^{\circ} \mathrm{F}$. -0.73 . secondly, volds, seen as the dark areas, are observed in the nickel beneath 


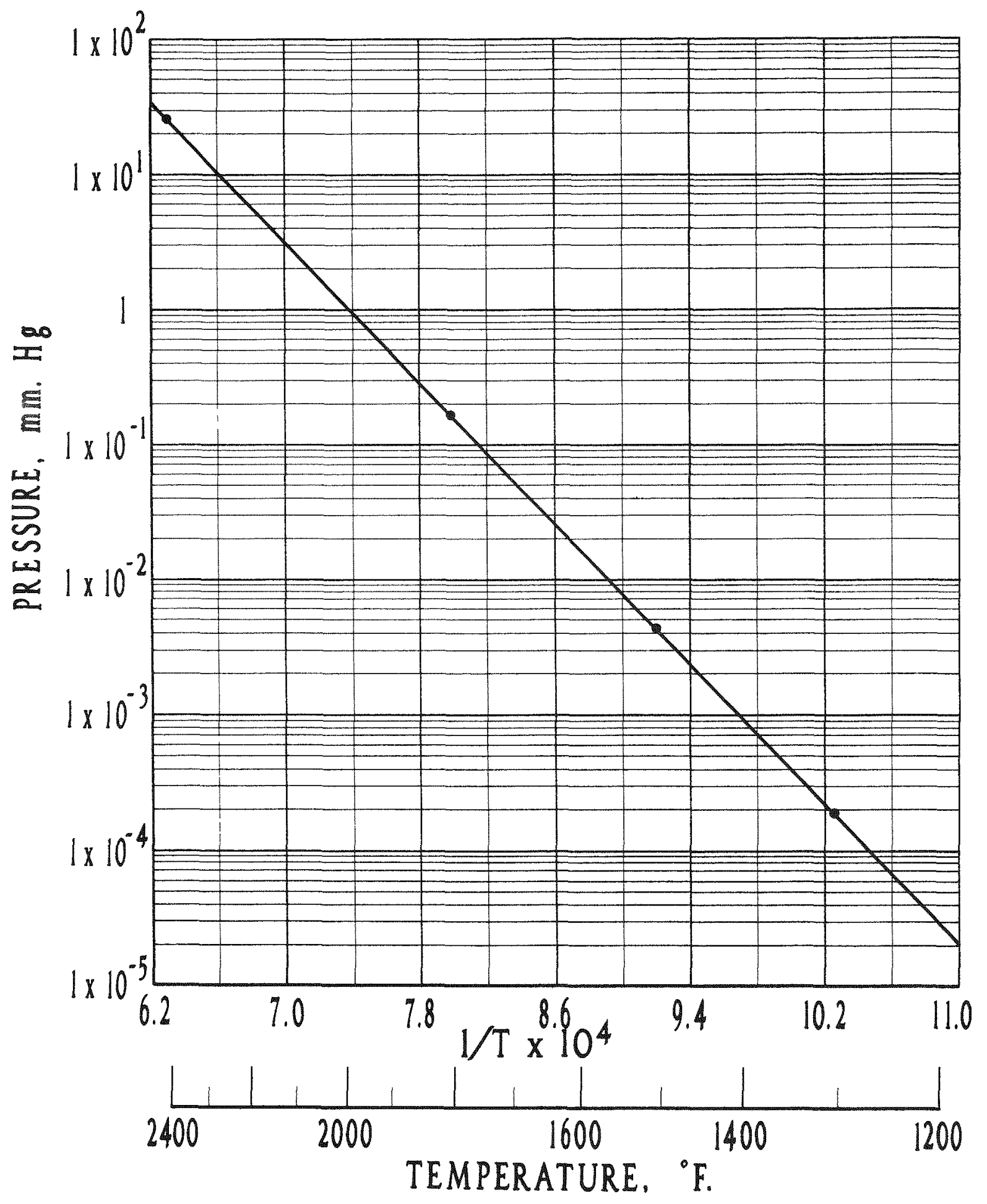

VAPOR PRESSURE OF NICKEL FLUORIDE

FIGURE 6 
the scale after both the 1500 and $1800^{\circ} \mathrm{F}$. exposures. These roids generally extend to about $1.5 \mathrm{mils}$ beyond the scale on the nickel exposed at $1500^{\circ} \mathrm{F}$. and about 7.5 mils beyond the scale on the nickel exposed at $1800^{\circ} \mathrm{F}$; these depths are to be compared to an average nickel penetration of about 0.17 and 0.87 mil calculated from $X$ ray absorption measurements of the thickness of the nickel fluoride film or discs from the former and latter exposures, respectively. The average depth of nickel penetration in the $1800^{\circ} \mathrm{F}$. investigation was caiculated from the total weight gain and geometric surface of the nickel discs to be somewhat greater, about 2.1 mils or $2-1 / 2$ times that calculated from the $X$-ray measurements. Thus, the rate of scale formation probably will not prove useful in forecasting equipment life at 1500 and $1800^{\circ} \mathrm{F}$. [Subsequent explaratory studies have indicated only generalized attack occurs at $1100^{\circ} \mathrm{F}$.]

The voids in the exposed nickel are associated with the grain boundaries in the metal. Since metal atoms are less firmly held at grain boundaries, attack by diffusion along grain boundaries is common on metals at high temperatures and occurs because of the attempt of the metal atoms to equalize the concentration gradient between the metal interior and the reaction zone. The operation of such a mechanism has a number of important implications:

1. As observed earlier, the rates of attack might be considerably higher during recrystallization and grain growth processes, and the film laid down under these conditions might be less protective than one laid down after the grain growth process has essentially stopped.

2. The severe grain boundary penetration observed may have occurred during the recrystallization and rapid grain growth periods; grain boundary penetration after the grain growth process becomes slow may proceed at a significantly lower rate.

3. The nickel will not be structurally strong and therefore must be used in the form of cladding on a stronger metal.

4. The addition of elements which inhibit grain growth would improve the structural properties and might increase the corrosion resistance, although such an increase in the corrosion resistance would be contrary to lower temperature experience.

Electron micrographs of carbon replicas of the nickel fluoride formed on the grade $A$ nickel at $1800^{\circ} \mathrm{F}$. are presented in figure 8 . The steps noted in the electron micrographs are typical crystal growth patterns. Here again, there is little evidence of cracks or flaws in the crystals themselves that would allow direct exposure of the underlying nickel to the corrosive gas phase. Although the size of a single crystal is not directly determinable from the electron micrographs, since complete crystals are too large to be shown, the crystals are of the order of 5 to 8 times as large 


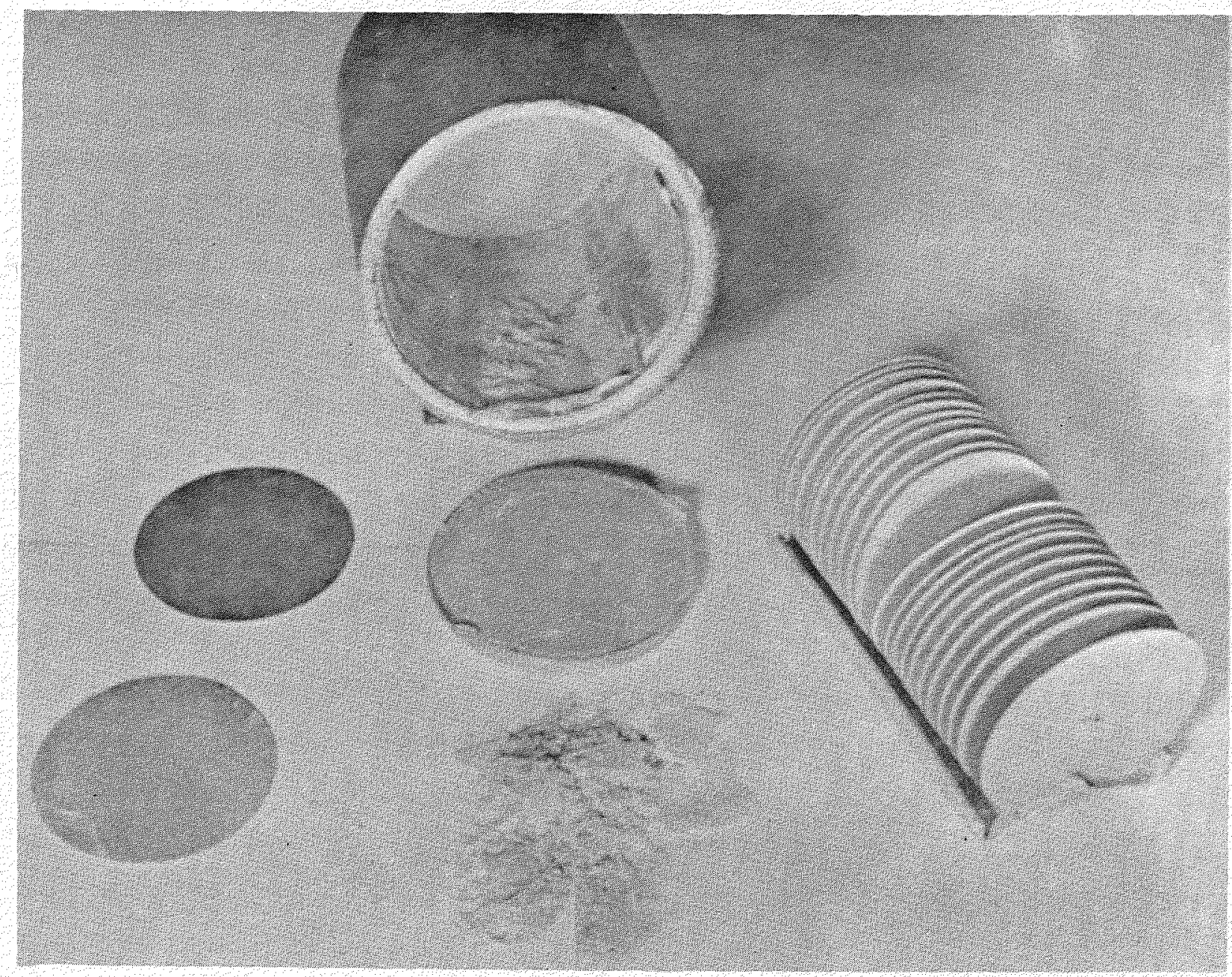

GRADE A NICKEL EXPOSED TO FLUORINE AT TEMPERATURES UP TO $1800^{\circ} \mathrm{F}$. FIGURE ? 

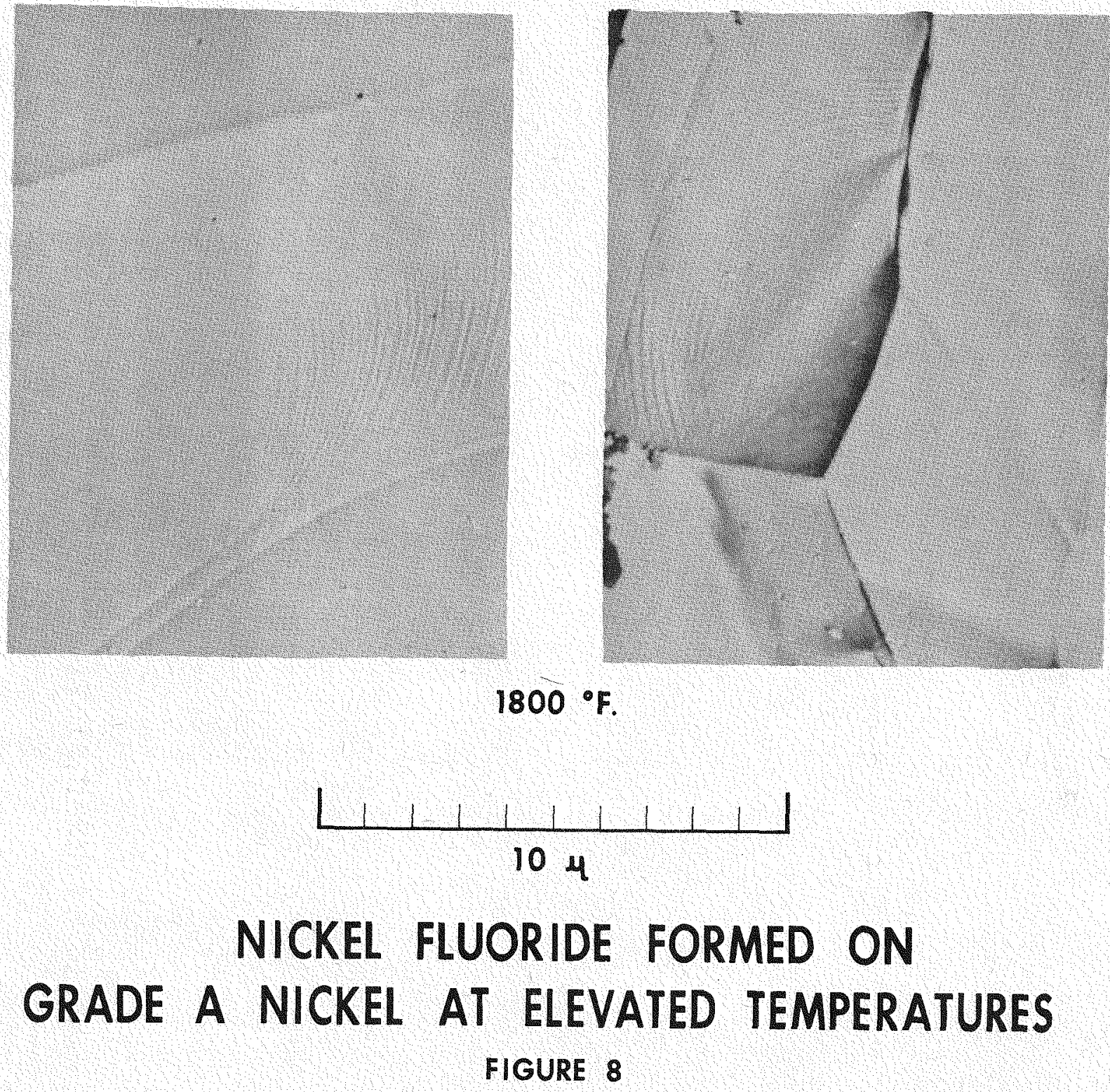

FIGURE 8 
8. those found from the $1500^{\circ} \mathrm{F}$. growth. The crystal dimensions are again about the same as the film thickness. This fact is believed to constitute further proof of the essentially single crystal thickness of these films. Visual comparison of the nickel fluoride formed at $1800^{\circ} \mathrm{F}$. With that formed at $1500^{\circ} \mathrm{F}$. can be made by comparing these electron micrographs with those shown in figure 4.

PART II. EXPOSURE OF REFRACTORY OXIDES AND A CERMET TO FLUORINE AT ELEVATED TEMPERATURES

Because metals of sufficient structural strength to be useful at tempera. tures as high as $2500^{\circ} \mathrm{F}$. hold little promise of withstanding the corrosive attack of fluorine and uranium hexafluoride at these temperatures, $a$ preliminary investigation of the corrosive resistance of certain refractory oxides whose resistance to fluorine and uranium hexafluoride at lower temperatures appeared adequate was undertaken. The oxides and the cermet selected for study contained $\alpha$ alumina $\left(\mathrm{Al}_{2} \mathrm{O}_{3}\right)$ as a principal constituent. Alphaalumina has been shown at this laboratory to have satisfactory resistance to fluorine and uranium hexafluoride at $200^{\circ} \mathrm{C}$. and at Argonne National Laboratory $(5,6)$ to have excellent resistance to fluorine up to $650^{\circ} \mathrm{C}$.

\section{Experimental}

Apparatus and Materials. Figure 9, excluding the uranium hexafluoride manl fold and the nickel sample discs, depicts the equipment used in this investigation. The reactor was constructed from $1-1 / 4$ minch seamless nickel tubing, 0.065 -inch wall, and was closed by means of a Teflon-gasketed flange at an extended distance from the furnace. The furnace was a Burrell Globar type which was maintained at a constant temperature by a Brown controlling and recording potentiometer through the use of a chromel-alumel thermocouple. Various shaped samples of acalumina, magnesium oxidew $\alpha-a l u m i n a$ spinel, and the cermet, $\alpha$ aluminamickel oxide-nickel, having geometric surface areas of $1-1 / 2$ to $2-1 / 4$ square inches were used. The $\alpha$ alumina was 98.86 per cent pure, the remaining 1.14 per cent consisting of alkaline earth binders. The ratio of the magnesium oxide to $\alpha$-alumina in the spinel was one to one. The cermet contained about 8 per cent free nickel and 8 per cent nickel oxide with the remaindex being $\alpha$ malumina.

Procedure. After the samples had been degreased with Freon-113, the X-ray diffraction pattern was measured for each. The samples were then weighed on an analytical balance, placed in a grade A nickel boat, and inserted into the reactor about midway of the furnace.

After leak-testing and evacuating the system, undiluted fluorine was admitted to the reactor to about one atmosphere absolute pressure and the furnace temperature was brought to and maintained at the desired level. Intermit. tently, at about one-hour intervals, the reactor was alternately evacuated and filled with a new shot of fluorine. 


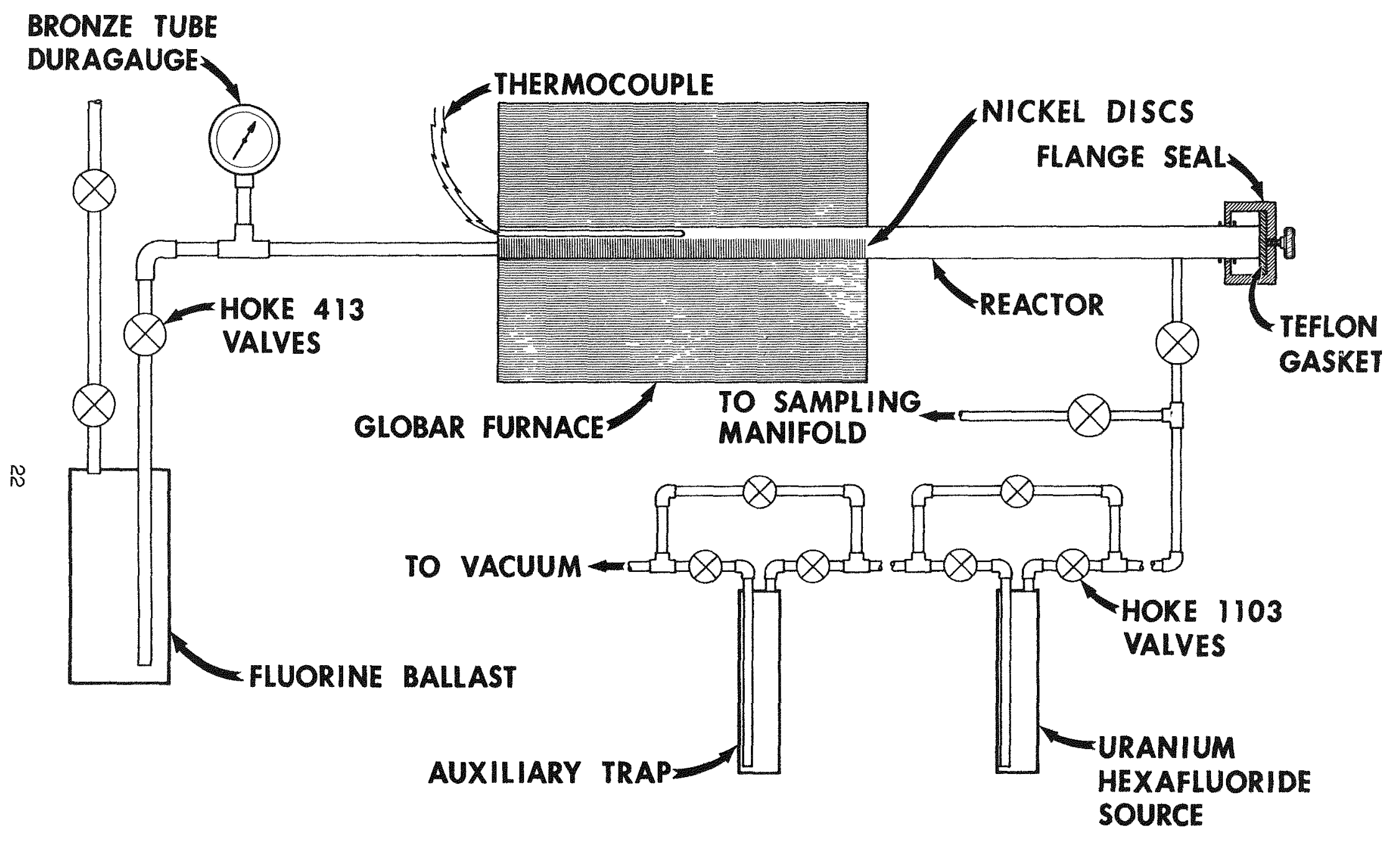

REACTOR AND MANIFOLD ASSEMBLIES

FIGURE 9 
At the conclusion of the first 24 hour exposure at $1340^{\circ} \mathrm{F}$, the veight change of each of the samples was determined. At the end of the total. exposure of 48 hours at $1340^{\circ} \mathrm{F}$, the samples were submitted for film thickness estimates by $X-r a y$ absorption and for $X$-ray diffraction measurements.

These samples were reinserted in the furnace, the systen was evacuated, and the samples were subsequently exposed to undiluted fluorine at about one atmosphere absolute pressure at $1500^{\circ} \mathrm{F}$. for an additional period of about 24 hours.

\section{Results and Discussion}

By visual observation the samples appeared to have undergone little deterioration due to the $1340^{\circ} \mathrm{F}$. Pluorine exposure; they retained their orlginal shape and only a change in color was noticeable. The weight gain experienced on each of the three samples during the first 24-hour exposure to undiluted fluorine at $1340^{\circ} \mathrm{F}$. is shown in table III; estimates of the film thickness by X-ray absorption measurements after 48 hours of exposure are also shown.

TABLE III

REFRACTORY OXIDES AND CERMET EXPOSURE TO UNDILUTED FLUORINE AT $1340^{\circ} \mathrm{F}$.

\begin{tabular}{|c|c|c|}
\hline Sample & $\begin{array}{l}\text { First } 24 \text {-Hour } \\
\text { Exposure } \\
\text { Weight Gain, } \\
\mathrm{mg} / \mathrm{sq} \text {. inch }\end{array}$ & $\begin{array}{l}\text { 48-Hour Exposure } \\
\text { F1lm Thickness by } \\
\text { X-ray Absorption, } \\
\text { A. } \\
\end{array}$ \\
\hline$\alpha-\mathrm{Al}_{2} \mathrm{O}_{3}$ (Alumina) & 2.72 & 50,000 \\
\hline$\alpha-\mathrm{AI}_{2} \mathrm{O}_{3} \cdot \mathrm{MgO}$ (spinel) & 10.4 & 80,000 \\
\hline$\alpha-\mathrm{Al}_{2} \mathrm{O}_{3} \cdot \mathrm{NiO} \cdot \mathrm{Ni}$ (Cermet) & 3.7 & $-\infty$ \\
\hline *Geometric surface area. & & \\
\hline
\end{tabular}

The weight gain on the cermet is of the same order of magnitude as that experienced on the $\alpha=a$ lumina while the weight gain exhibited by the spinel is about four times as large.

Since, after the second 24 -hour exposure at $1340^{\circ} \mathrm{F}$, conversion of the sample surfaces to the respective metal fluorides was ascertained by $X-r a y$ diffraction patterns of the films, an estimate of the speed of conversion of the $\alpha$ alumina to aluminum trifluoride can be made from the following equation and the weight gain assuming that all the aluminum fluoride which was formed adhered to the oxide. 


$$
\mathrm{Al}_{2} \mathrm{O}_{3}+3 \mathrm{~F}_{2} \rightarrow 2 \mathrm{AIF}+\frac{3}{2} \mathrm{O}_{2}
$$

According to this calculation about $35,000 \mathrm{~A}$. of aluminum fluoride had been formed on the alumina through the displacement of the oxygen by fluorine at $1340^{\circ} \mathrm{F}$. in 24 hours. The $X$-ray absorption estimate of $a$ 5-micron film after 48 hours of treatment is considered a fair check on the calculated 3.5 microns after the 24 -hour treatment.

The same samples were exposed to undiluted fluorine at $1500^{\circ} \mathrm{F}$. for 24 hours with no drastic deterioration. They were contaminated somewhat by nickel fluoride, but showed no evidence of nomuniform attack.

On the basis of the formation of $35,000 \mathrm{~A}$. of aluminum fluoride in 24 hours with undiluted fluorine at $1340^{\circ} \mathrm{F}$, a rather arbitrary comparison of the $\alpha$-alumina with nickel can be made. The formation of a film of $35,000 \mathrm{~A}$. of aluminum fluoride is equivalent to a penetration of $17,000 \mathrm{~A}$. of $\alpha$-alumina per day at $1340^{\circ} \mathrm{F}$, and this can be compared to a penetration of about $16,000 \mathrm{~A}$. of nickel per day experienced at $1300^{\circ} \mathrm{F}$. under approximately $1 / 2$ atmosphere absolute fluorine pressure. of course, it must be kept in mind that the nickel had several hundred thousand angstroms of nickel fluoride already present before these measurements were made.

In summary, based on these preliminary data, the average depths of penetram tion of $\alpha$-alumina and nickel would indicate that the $\alpha$-alumina is comparable to nickel in the region of $1300^{\circ} \mathrm{F}$, and is worthy of further examination.

PART III. THE EXPOSURE OF NICKEL COATED WITH A HEAVY FILM OF NICKEL FLUORIDE TO URANTUM HEXAFLUORIDE AT ELEVATED TEMPERATURES

A. Exploratory Study

Experimental

Apparatus and Materials. The apparatus employed in the first investigation of the corrosive action of uranium hexafluoride on nickel coated with a heavy nickel fluoride film is presented in figure 9 . Both the fluorine and uranium hexafluoride manifolds, as well as the reactor assembly, are schematically presented. The nickel discs, 5/8-inch in diameter and 25 mils thick, were punched from grade A nickel sheet and were supported in a vertical position in the reactor by means of a slotted rack which was formed from 1/16-inch grade A nickel sheet. The reactor was constructed from 1-1/4-inch seamless nickel tubing with a 0.065 -inch wall. The thermowell in the reactor was $1 / 4$-inch seamless nickel tubing of 0.065 -inch wall. All joints in the reactor assembly were welded with nickel except for the end which was sealed by means of a Teflon-gasketed flange and was maintained at amblent room temperature. A Burrell Globar furnace was used to heat the reactor which was maintained at the desired temperature level by a recording and controlling Brown potentiometer operating with a chromel $\Rightarrow$ alumel thermocouple. 
Procedure. The samples, rack, and reactor were degreased with Freon-113 and dried; every fifth sample disc was weighed on an analytical balance; all the discs were placed in a vertical position in the rack; and the rack and discs were inserted into the reactor to the central portion of the furnace. After evacuating the system, fluorine was admitted from a ballast rolume and the temperature was increased to about $1300^{\circ} \mathrm{F}$. At about one-hour intervals the reactor was evacuated and a fresh shot of fluorine was admitted to about one atmosphere absolute pressure. During the sixth and last hour of the fluo$r$ ine exposure the temperature of the reactor was increased to $1500^{\circ} \mathrm{F}$. After the fluorine exposure, every fifth disc was reweighed for an average fluoride film determination; the rack and discs were reinserted into the reactor; and the system was thoroughly evacuated. Then the uranium hexafluoride source, maintained at ambient room temperature, was allowed to exert 1 ts vapor pres sure of about 12 centimeters of mercury absolute into the reactor, following which the temperature of the reactor was raised to 1500 or $1800^{\circ} \mathrm{F}$. and maintained there. At the conclusion of an exposure the power was shut off the furnace, and the uranium hexafluoride was frozen into the source container with carbon dioxide-Freon-113 slush while the reactor was cooling to about $500^{\circ} \mathrm{F}$. The reactor was then evacuated through an auxillary carbon dioxide-Freon-113 slush-cooled trap during the period required for cooling to room temperature. The consumption of uranium bexafluoride during the exposure was determined by the total welght loss of the uranium hexafluoride source. At the conclusion of the exposures the sample was examined visually; a final weight was obtained on the previously weighed discs; chemical analyses for total uranium and total fluoride were performed on the discs; Identification of the corrosion deposits were made by $\mathrm{X}$-ray diffraction techniques; the metal was examined metallographically; and the fluoride film on the nickel discs from the center of the reactor were replicated with carbon and examined by electron microscopy.

\section{Results and Discussion}

The average nickel fluoride film formed on the grade A nickel discs previous to the first uranium hexafluoride exposures, as determined by the average weight gain of the discs, was calculated to be $37,000 \mathrm{~A}$. Subsequent successive uranium hexafluoride consumption rates on two exposures of short duration by the grade A nickel at 1500 and $1800^{\circ} \mathrm{F}$, as determined by the weight loss of the source are presented in table IV. The $1500^{\circ} \mathrm{F}$. rate was obtained during an initial 24-hour exposure; the sample was then exposed an additional 42 hours at $1500^{\circ} \mathrm{F}$. and 60 hours at $1800^{\circ} \mathrm{F}$. before the 19.7 -hour rate at $1800^{\circ} \mathrm{F}$. was determined. Thus the nickel sample was exposed to the uranium hexafluoride atmosphere for a total of 66 hours at $1500^{\circ} \mathrm{F}$. and about 80 hours at $1800^{\circ} \mathrm{F}$. before termination of the investigation. 
URANIUM HEXAFLUORIDE CONSUMPTION RATE BI GRADE A NICKEL COATED WITH A HEAVY NICKEL FLUORIDE FILM AT ELEVATED TRMPERATURES

\begin{tabular}{|c|c|c|c|}
\hline $\begin{array}{c}\text { Exposure TIme, } \\
\text { hours } \\
\end{array}$ & $\begin{array}{l}\text { Consumption Rate, } \\
\mathrm{mg} \cdot \mathrm{U} / \mathrm{sq} . \mathrm{ft} . * / \text { day } \\
\end{array}$ & $\begin{array}{l}\text { Temperature of } \\
\text { Exposure, }{ }^{\circ} \text {. }\end{array}$ & $\begin{array}{c}\text { Average Nickel } \\
\text { Present at st8 } \\
\text { sxposure, }\end{array}$ \\
\hline 24 & 737 & 1500 & 37,000 \\
\hline 19.7 & 604 & 1800 & $=-$ \\
\hline
\end{tabular}

*Geometric Surface Area.

At the conclusion of the $1800^{\circ} \mathrm{F}$. exposure, the reactor was opened and the rack and discs were removed. A photograph of some of the discs after exposure to uranium hexafluoride at both 1500 and $1800^{\circ} \mathrm{F}$. is presented in figure 10. The discs and rack from the central and bottest zone of the furnace visually appeared free of both nickel fluoride and the lower valent uranium fluorides; these discs appear across the bottom of the photograph. Each of these center discs appeared to have alternately dull etched and bright shiny plate spots over the surface. The corrosion products appeared in copious quantities both on the discs and as loose scale toward the cooler ends of the reactor. Some of the discs from each end of the reactor are shown to the left and right side of the photograph, respectively. The increase in corrosion products on these discs from the center toward the ends of the reactor can be observed here, although it could be seen much more distinctly from the actual colors of the corrosion products. An untreated disc is included in the center of the photograph for comparison. Table $V$ presents estimates of the relative quantities of products on the discs obtained from $X$-ray diffraction measurements as well as the quantity of uranium on adjacent discs obtalned by chemical analysis. The $X-r a y$ diffraction patterns indicated only the expected products, uranium tetrafluoride and nickel fluoride, were present. The increase in the quantity of uranium found on the discs proceeding from the center toward the ends of the reactor is shown by these data.

Most of the nickel fluoride and uranium tetrafluoride found on the discs in the cooler sections of the reactor was nonadherent as though it had been deposited from the gas phase. The appearance of the discs is understandable in view of the relative vapor pressures of uranium tetrafluoride and nickel fluoride. The vapor pressure of uranium tetrafluoride as plotted in figure 11 presents a composite of liquid data recently determined by Langer (3) and those of the solid taken from earlier measurements by Ryon and Twichell (4). Although the vapor pressure is plotted in its usual relationship with temperature in reciprocal degrees Kelvin, an auxiliary Fabrenheit scale is included for convenient reference. The points shown are not experimental values but rather those of particular interest in this investigation. At $1500^{\circ} \mathrm{F}$. the vagor pressure of the solid uranium tetrafluoride is seen to be 15 microns, and at $1800^{\circ} \mathrm{F}$. it becomes $1.6 \mathrm{~mm}$. These can be compared with the vapor pressures of nickel fluoride of 5 microns and 

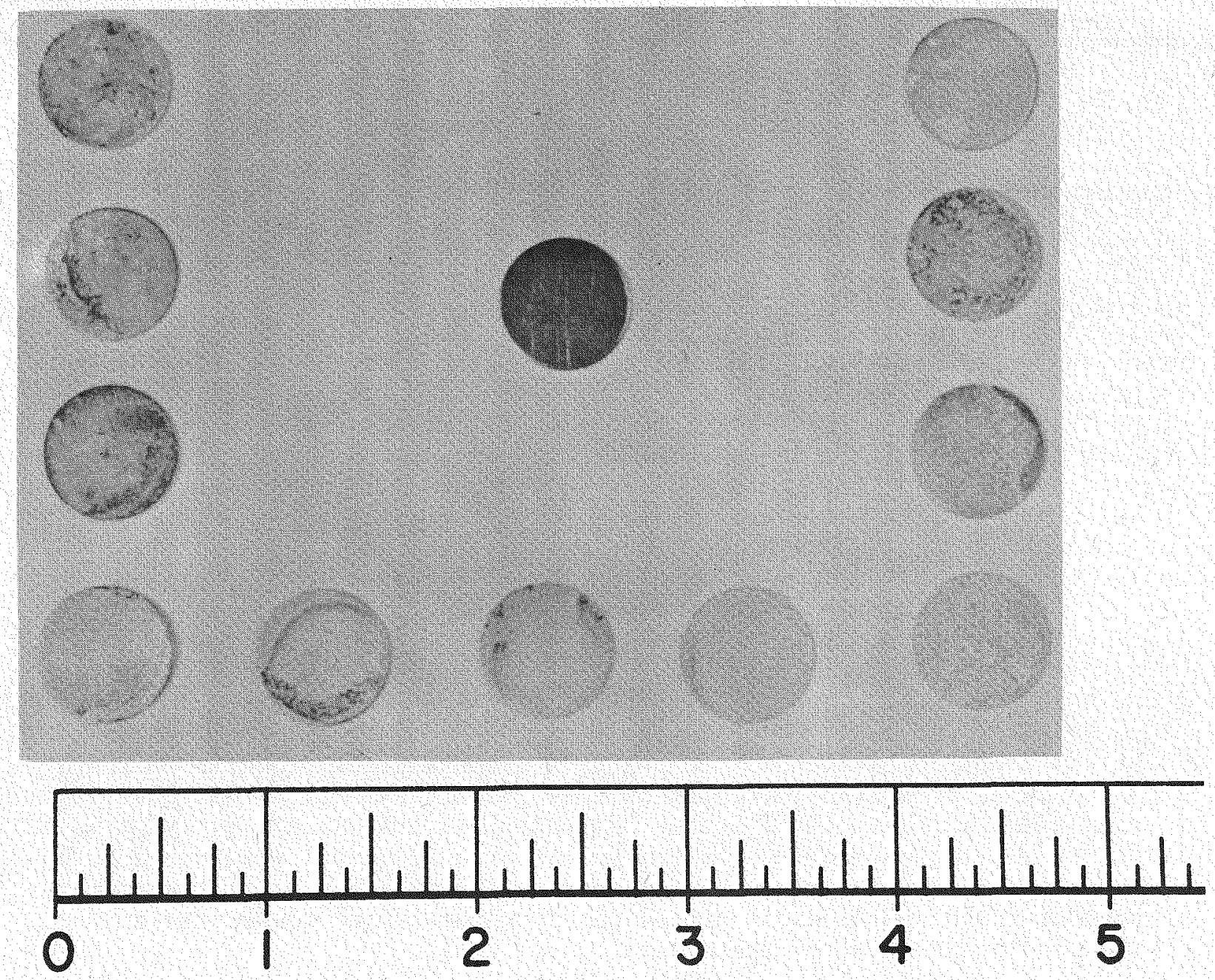

GRADE A NICKEL EXPOSED TO URANIUM HEXAFLUORIDE AT ELEVATED TEMPERATURES

FIGURE 10 
TABLE V

DISTRIBUTION OF $\mathrm{NIF}_{2}$ AND URANTUM ON GRADE A NICKEL FROM UF 6 EXPOSURE

\begin{tabular}{|c|c|c|c|c|}
\hline DIsC & Residual & & ition of I & \\
\hline $\begin{array}{l}\text { Number or } \\
\text { Position } 1 \\
\end{array}$ & $\begin{array}{c}\text { Uranium, } \\
\text { mg. U/disc }\end{array}$ & $\begin{array}{c}\text { NiFes } \\
\text { per cent }\end{array}$ & $\begin{array}{c}\mathrm{UF}_{4,} \\
\text { per cent }\end{array}$ & $\begin{array}{c}\text { NI, } \\
\text { per cent }\end{array}$ \\
\hline 4 & $-\infty$ & 30 & 70 & $-\infty$ \\
\hline 5 & 0.8 & $-\infty$ & $=-\infty$ & $-\infty$ \\
\hline $5-10^{3}$ & $-\infty$ & 85 & 15 & $-\infty$ \\
\hline 9 & $=-$ & 80 & 10 & 10 \\
\hline 10 & 1.43 & $-\infty$ & $-\infty$ & $-\infty$ \\
\hline $10-15^{3}$ & $=0$ & 90 & 10 & $-\infty$ \\
\hline 20 & 0.04 & $\infty$ & $=-$ & $-\infty$ \\
\hline 30 & 0.03 & $-\infty$ & $=\infty$ & $-\infty$ \\
\hline 40 & 0.12 & - & $-\infty$ & $-\infty$ \\
\hline 42 & -- & 50 & -- & 50 \\
\hline 46 and 47 & $0.02^{4}$ & $-\infty$ & $\infty$ & - \\
\hline 50 & 0.04 & - & $=$ & - \\
\hline 51 & $-\infty$ & $100^{5}$ & - & $-\infty$ \\
\hline 60 & 0.80 & $-\infty$ & $-\infty$ & $-\infty$ \\
\hline 70 & 5.94 & $-\infty$ & $-\infty$ & $-\infty$ \\
\hline 74 & $-\infty$ & 40 & 60 & $-\infty$ \\
\hline 79 & $-\infty$ & 15 & 85 & $=\infty$ \\
\hline 80 & 1.95 & - & $=-$ & - \\
\hline 84 & $\infty$ & 70 & 30 & $-\infty$ \\
\hline $85-89^{3}$ & $\infty$ & 1005 & $-\infty$ & $\infty$ \\
\hline 89 & 4.04 & $-\infty$ & $\infty$ & $-\infty$ \\
\hline
\end{tabular}

1. The discs are numbered starting from the end of the reactor near the fluorine entry or opposite the UF 6 entry.

2. Nickel was inadvertently removed with the corrosion products.

3. Powder in the vicinity of discs as indicated.

4. Average figure - two discs were run as one determination.

5. X-ray diffraction cannot identify materials constituting less than about 5 weight per cent of the total. 


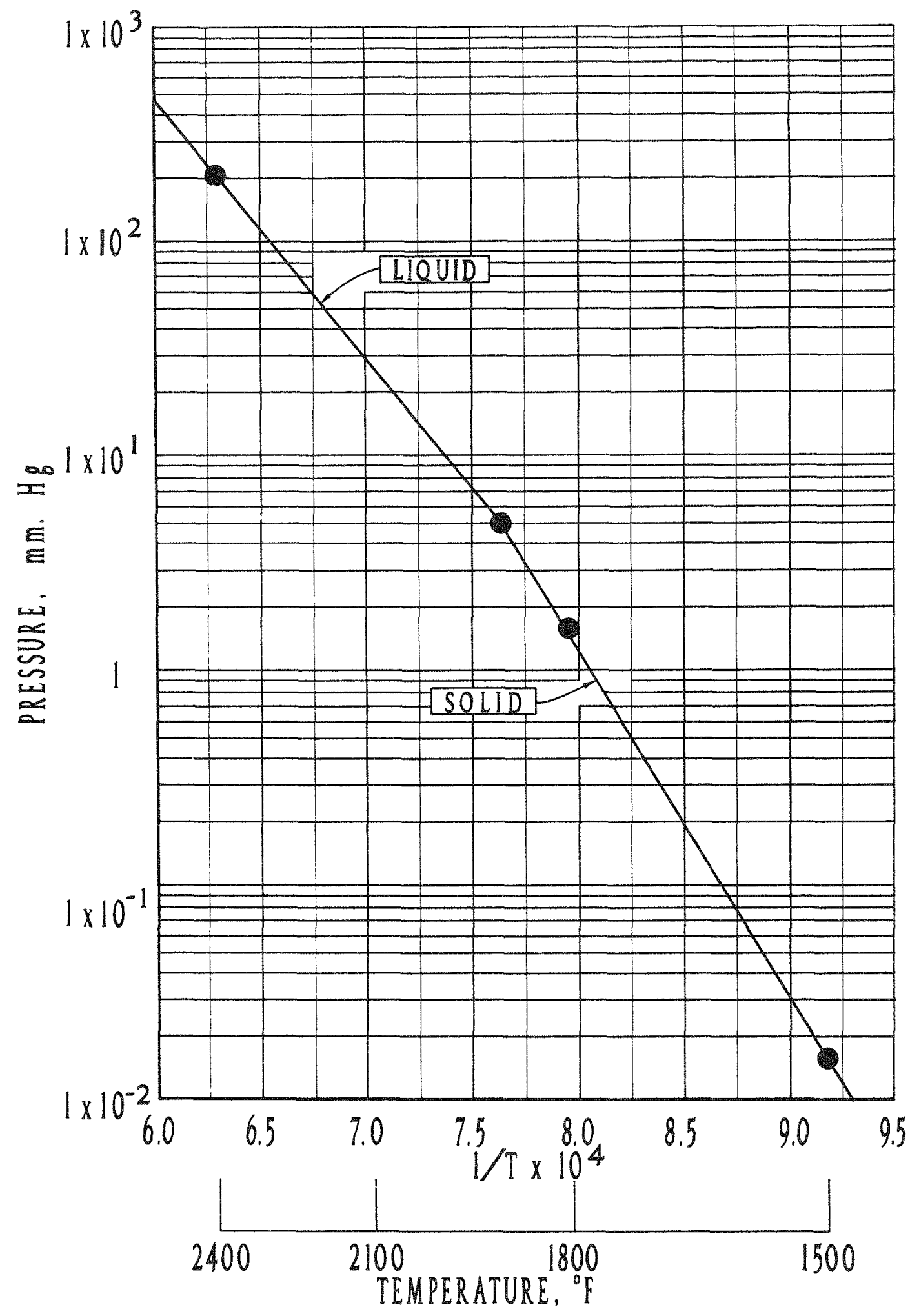

VAPOR PRESSURE OF URANIUM TETRAFLUORIDE

FIGURE 11 
approximately $0.2 \mathrm{~mm}$. at 1500 and $1800^{\circ} \mathrm{F}$, respectively.

Although the centra.lly located discs exposed to uranium hexafluoride were visually free of both lower valent uranium fluorides and nickel fluoride, a small amount of uranium was found on these discs by analysis, and considerably more nickel fluoride was present, table $V$. The relative quantities of uranium tetrafluoride and nickel fluoride found on the rilckel discs in the center of the reactor are of the order expected from the relative vapor pressures of these compounds at $1800^{\circ} \mathrm{F}$.

The nickel fluoride film present on these center discs was estimated from $X$-ray absorption measurements to be of the order of a micron in thickness; the average thickness calculated from analyses of the center discs for total fluoride was $7,090 \mathrm{~A}$. or 0.7 of a micron.

Metallographic examination of cross sections of the $5 / 8$-inch diameter nickel discs that were exposed to uranium hexafluoride has been performed. Photomicrographs of the cross sections of three of the discs exposed to uranium hexafluoride at $1500^{\circ} \mathrm{F}$, and later at $1800^{\circ} \mathrm{F}$. are presented on the right side of Pigure 12. The photomicragraph at the top right is cross section of a disc that was located near the cooler end of the reactor during exposure to the uranium hexafluoride. The photomicrograph at right center is a cross section of a disc that was exposed at about $1 / 3$ the total furnace distance from the end, and the bottom photomicrograph is of a disc from the center or hottest zone of the furnace. In the top photomicrograph very little recrystallization of the nickel can be noted as compared to the unexposed blank at top left; the middle right disc has recrystallized to about the same extent as that from the $1500^{\circ} \mathrm{F}$. fluorine exposure, midale left; and the recrystallization of the nickel disc from the center of the reactor which was exposed to uranium hexafluoride at $1800^{\circ} \mathrm{F}$. is quite comparable to that experienced in the nickel that was exposed to fluorine at $1800^{\circ} \mathrm{F}$, bottom left. Voids are beginning to appear along the grain boundaries of the nickel discs exposed to uranium hexafluoride at 1500 to $1600^{\circ} \mathrm{F}$, but are much less evident than those experienced in the nickel exposed at $1500^{\circ} \mathrm{F}$. to fluorine. The nickel dises exposed to uranium hexa. fluoride at $1800^{\circ} \mathrm{F}$. exhibit distinct volds along the grain boundaries in the nickel near the nickel fluoride scale similar to those experienced in the $1800^{\circ} \mathrm{F}$. fluorine exposure. The voids produced during the uranium hexa Pluoride exposure are smaller and less numerous, as noted from the bottom two photomicrographs of ilgure 12, however, they appear to extend to a slightly greater depth, 9 mils compared to 7.5 mils in the fluorine exposure.

The two uranium hexafluoride consumption rates of 737 and 604 me. 0/sq. ft./day, successively determined at 1500 and $1800^{\circ} \mathrm{F}$, respectively, seem contrary to the expected trend when related only to exposure tempera. ture and film thickness. However, several factors, the importance of which is presently unknown, may contribute to the observed behavior. An excellent opportunity for annealing of the samples prior to the latter rate measure. ment was afforded by the interim beat treatment. In view of Doescher's observations (1), the protective character of the thinner nickel fluoride film present on the hotter, center discs during the $1800^{\circ} \mathrm{F}$. exposure may 

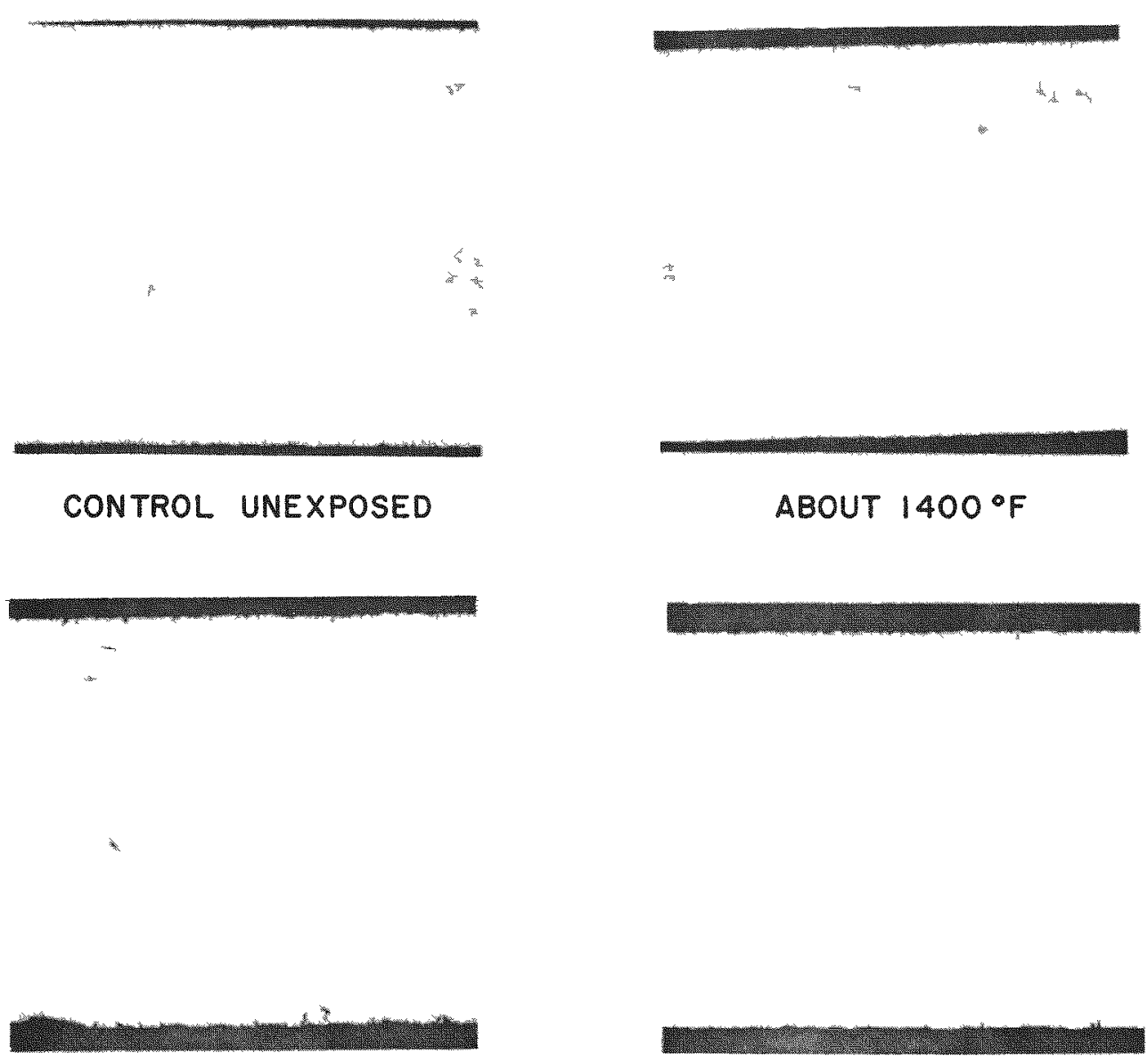

$1500^{\circ} \mathrm{F}$

$$
\text { ABOUT } 1500-1600^{\circ} \mathrm{F}
$$
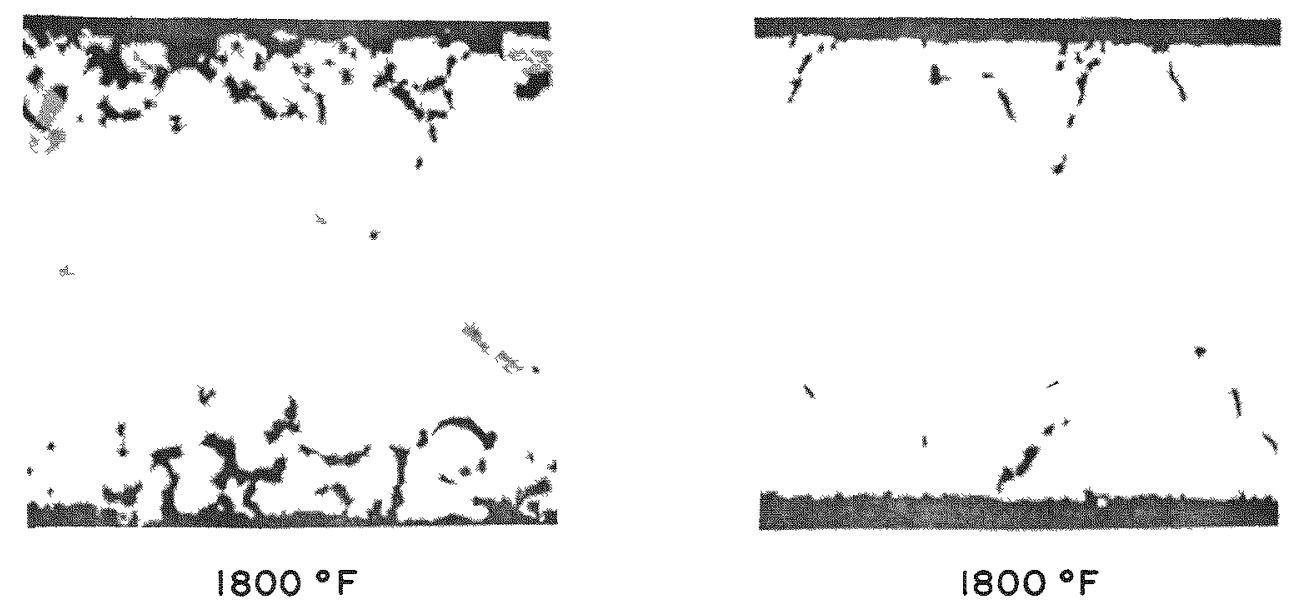

FLUORINE EXPOSURE

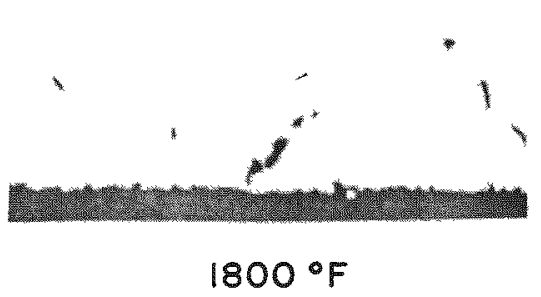

URANIUM HEXAFLUORIDE EXPOSURE

GRADE A NICKEL EXPOSED TO FLUORINE AND URANIUM HEXAFLUORIDE AT ELEVATED TEMPERATURES FIGURE 12 
have been superior to that of the thicker film protecting these discs during the $1500^{\circ} \mathrm{F}$ 。 exposure. Also the heavier coating of nickel and uranium fluorides defosited from the vapor phase on the cooler, outer discs may have afforded some additional protection to these discs during the latter rate measurement.

Furthermore, the fact that the center discs weighed about $0.03 \mathrm{~g}$. more with only a $7000 \mathrm{~A}$. film of nickel fluoride than the same discs immediately after stabilization with a film of $37,000 \mathrm{~A}$. thickness suggests that a mass transfer of material other than nickel fluoride is involved.

Since the uranium tetrafluoride found on the center discs accounts for only an insignificant fraction of the observed welght gains, metallic nickel must have been deposited on these discs from the vapor phase. In a few instances, a bridge of nickel "whiskers" between the edges of adjacent discs in the hottest zone was actually observed. One hypothesis which might explain these observations is that a high temperature reversal of the corrosion reaction occurs at low uranium hexafluoride pressures which involves nickel fluoride vapor from the reactor wall. Such a reaction would be represented by the following equation:

$$
\mathrm{NiF}_{2(\mathrm{~g})}+\mathrm{UF}_{4(\mathrm{~s})} \rightleftarrows \mathrm{Ni}(\mathrm{s})+\mathrm{UF}_{6(\mathrm{~g})} \uparrow
$$

Figure 13 presents an electron micrograph of a carbon replica of the nickel fluoride remaining on one of the center discs after the 1500 and $1800^{\circ} \mathrm{F}$. uranium hexafluoride exposures. While the replica can be observed to have been torn during the replication, the nickel fluoride is shown to exhlbit the same type crystal growth steps as was noted to have occurred during the $1800^{\circ} \mathrm{F}$. fluorine exposure. (See figure 8.) The crystal size appears to be intermediate between that which was formed with fluorine at $1500^{\circ} \mathrm{F}$. and that which was formed with fluorine at $1800^{\circ} \mathrm{F}$.

\section{B. Uniform Temperature Exposure}

Some rate data from a second exploratory exposure of grade A nickel to uranium hexafluoride at elevated temperature is now available and is discussed below. This exposure is continuing*.

\section{Experimental}

Equipment and Procedure. The equipment depicted previously in figures 1 and 2 was used to lay down an average nickel fluoride film of 74,000 A. on an all grade A nickel sample consisting of the rack, reactor, and twenty three discs, $25 \mathrm{mils}$ thick and 2.7/16 inches in diameter. A manifold shown in figure 14 was then used to expose, in the manner previously described, the nickel samples to $12 \mathrm{~cm}$. absolute pressure of uranium hexafluoride at $1800^{\circ} \mathrm{F}$. for 20 hours.

\footnotetext{
*This run is now complete and the results reported on page 36 have been revised to take into account the later observations.
} 


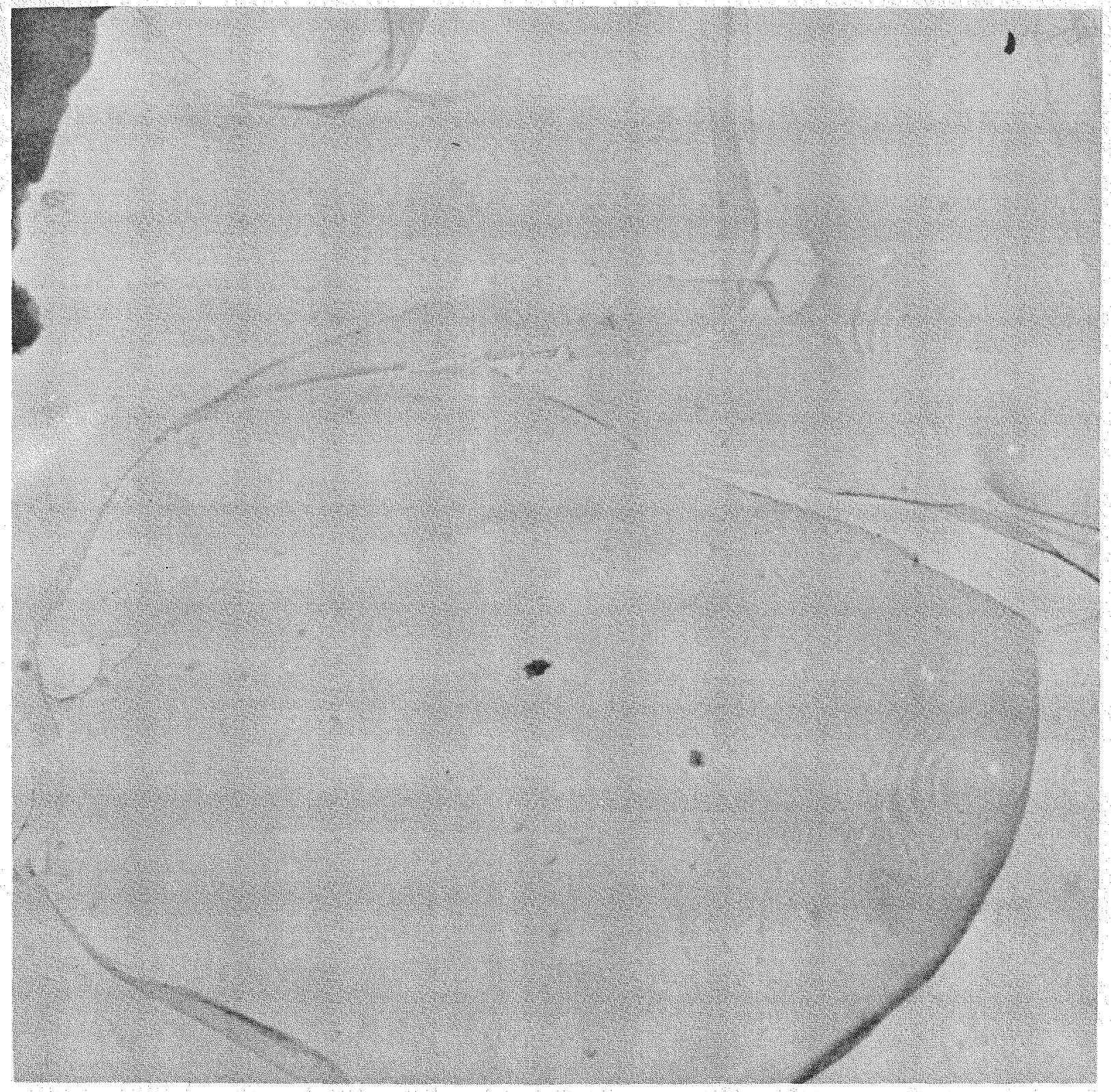
$1800^{\circ} \mathrm{F}$.

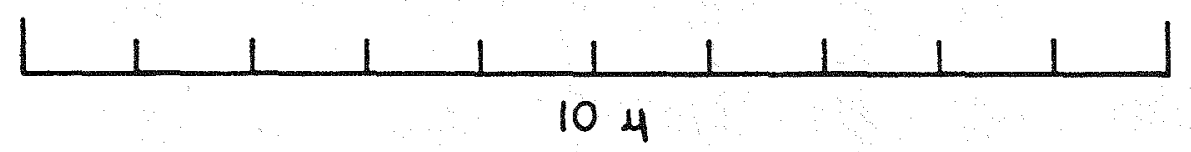

NICKEL FLUORIDE FORMED ON GRADE A NICKEL AT ELEVATED TEMPERATURES

FIGURE 13 


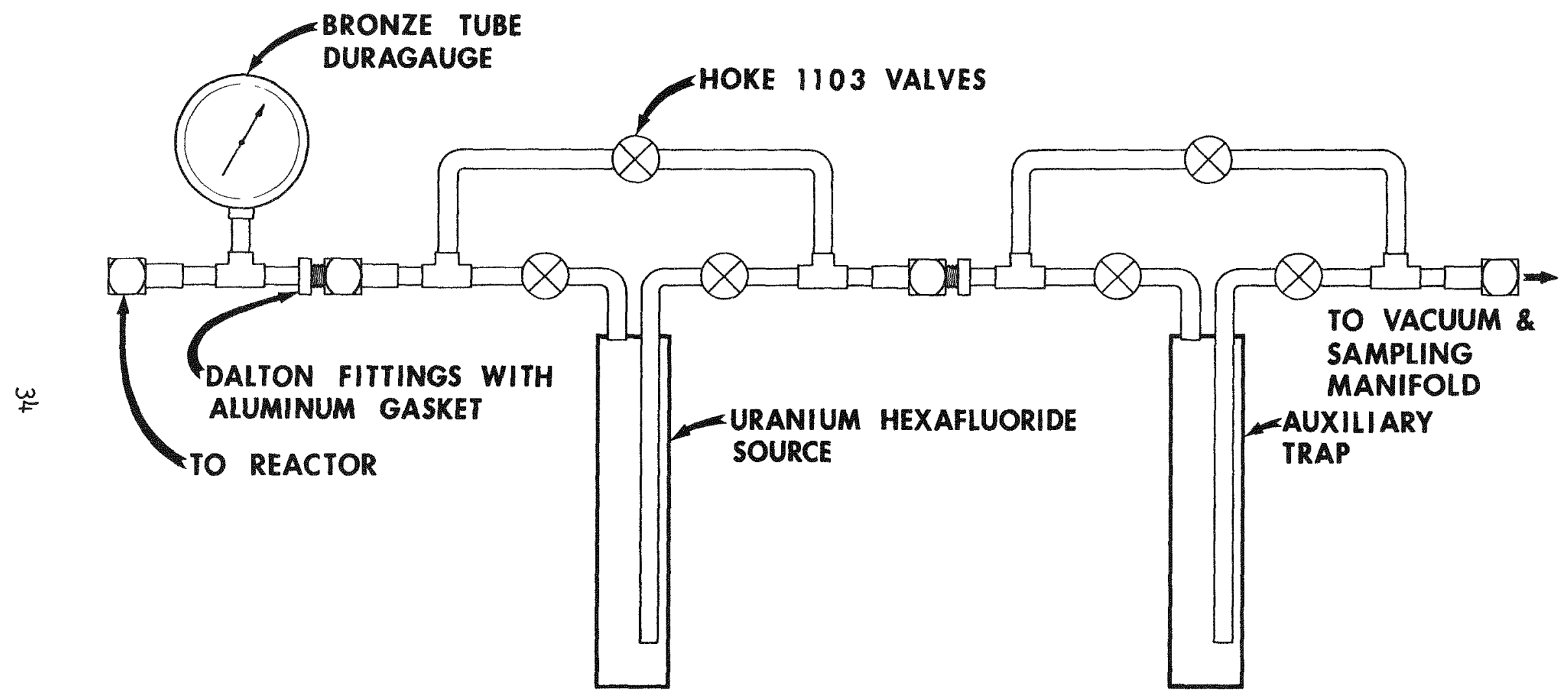

\title{
PRIMARY MANIFOLD
}

\author{
FIGURE 14
}


The initial consumption rate of the uranium hexafluoride at $1800^{\circ} \mathrm{F}$. determined from the loss in weight of the source was $811 \mathrm{mg}$. U/sq. ft./day which may be compared to the consumption rate previously experienced at $1800^{\circ} \mathrm{F}$. on the $5 / 8$-inch nickel aiscs of $604 \mathrm{mg}$. U/sq. ft./day. The agreement is reasonably good in view of the facts that the temperature uniformity during the previous investigation was inherently poor, and in the earlier run the samples were exposed at $1500^{\circ} \mathrm{F}$. for a significant time before the $1800^{\circ} \mathrm{F}$. exposure. However, at $1800^{\circ} \mathrm{F}$. the protection initially offered by the heavy nickel fluoride film is lost as the exposure continues; and after the passage of this initial period, during which a relatively low rate of reaction of uranium hexafluoride is experienced, rapid deposition of lower uranium fluorides (principaliy uranium tetrafluoride in this case) occurs. Consequently, the use of nickel to contain uranium hexafluoride at $1800^{\circ} \mathrm{F}$. or above is unpromising because of the volatility and instability of the nickel fluoride and the intergranular nature of the attack on the metal.

Still the relatively low consumption rate of uranium hexafluoride at $1800^{\circ} \mathrm{F}$. on nickel during the period in which a nickel fluoride film was known to be present holds promise in that it does indicate nickel may be employed as a container for uranium hexafluoride to as high a temperature as a stable nickel fluoride film can be produced. Since the volatility of nickel fluoride decreases rapidly with decreasing temperature, a sufficiently stable nickel fluoride film might be obtained at temperatures near enough to $1800^{\circ} \mathrm{F}$. to be useful.

\section{INDICATED FUTURE INVESTIGATIONS}

An investigation will be made to determine the extent of formation of voids in nickel thermally treated at high temperatures in an inert atmosphere or in vacuo rather than in an atmosphere of fluorine or uranium hexafluoride. Metallurgical treatment of the nickel at high temperatures to recrystallize it prior to the exposure to the corrosive atmosphere may result in an initially more passive nickel surface. Investigations of the resistance to corrosion of alloys of nickel which hold promise of reducing or preventing the attack along the grain boundaries will be carried out. Some alloys of nickel that are not as resistant to attack by fluorine and uranium hexafluoride at lower temperatures will be investigated for their resistance at high temperatures, since the type of grain boundary attack experienced. by nickel at elevated temperature suggests that one or more of these alloys may exhibit a more general but less penetrating attack. Pure samples of nickel prepared by vacuum melting will be investigated at high temperatures. An empirical theory of the cause of attack along the grain boundarles holds that attack occurs in these locations due to the minor impurities which are thrown out of the crystal along the grain boundaries during high temperature recrystallization. 
The resistance of nickel to Iluorine and uranium hexafluoride $w 111$ be determined at temperatures higher than $1800^{\circ} \mathrm{F}$. to determine the temperature at which the rate of attack is so excessive that further consideration is unwarranted*.

The pressure dependence of the fluorine attack on nickel w111 be investigated, particularly at pressures greater than one atmosphere absolute and at temperatures of $1500^{\circ} \mathrm{F}$, and above. The pressure dependence of the fluorine consumption rate at $1500^{\circ} \mathrm{F}$. Will be investigated more thoroughly to determine if changes in the character of the nickel fluoride and/or the nickel are responsible for the observed shift in the pressure dependency and the con sumption rates at this temperature as compared to those observed at $1300^{\circ} \mathrm{F}$.

The pressure dependence of the reaction of uranium hexafluoride with nickel at elevated temperatures will also be determined.

From the preliminary data obtained, further investigations of the refractory oxides, particularly alpha-aluminum oxide, with fluorine and uranium hexafluoride at elevated temperatures appear to be in order.

In addition, the following investigations appear to be worthwhile:

1. Experiments utilizing circulating fluorine and/or uranium hexafluoride at elevated temperatures.

2. Fundamental studies of stabilization procedures. There are indications in the literature (1) that certain variations employed in the production of nickel fluoride films appreciably affect the protective character of the film.

\section{Acknowledgement}

The authors wish to express their appreciation to W.W. Harris, F. N. Bensey, P.W. Pickrell, and Frances Ball of the Physics Department for their assistance in the $\mathrm{X}$-ray diffraction and electron microscopic studies and to $K . T$. Ziehlke and Allene George of the Metallurgy Department for the metallographic examinations.

* In view of recent results, future studies will be largely confined to temperatures below $1800^{\circ} \mathrm{F}$. 


\section{BIBLIOGRAPHY}

1. Doescher, R. N., The Heat of Dissociation of Fluorine, Jet Propulsion Laboratory, California Institute of Technology, Pasadena, California, November 2, 1951, JPL -PR-20-61. (NP-4003).

2. Faber, M., Meyer, R.T., and Margrave, J. L., "rhe Vapor Pressure of Nickel Fluoride", Jo Phys. Chem, 62, 883 (1948).

3. Langer, S. and Blankenship, F。F。, "The Vapor Pressure of Uranium Tetrafluoride", Abstracts of Papers, 135th Meeting, American Chemical Society, Boston, Massachusetts, April 1959.

4. Ryon, A. D。 and Twichel1, L。 P., Vapor Pressure and Related Physical Constants of Uranium Tetrafluoride, Union Carbide Nuclear Company, X-12 Plant, July 25, 1947 (Document No. H-5.385.2).

5. Steindler, M.J. and Vogel, R. Cog "Corrosion of Metals in Gaseous Fluorine at Elevated Temperatures", Chemical Engineering Division Summary Report for January, February, March, 1956 , Argonne National Laboratory, May 2, 1956, pp. $34-39$ (ANL-5560).

6. Steindler, M.J., "Investigation of Possible Materials to be Used in the Preparation of Plutonium Hexafluoride" Chemical Engineering Division Summary Report for April, May, June, 1956, Argonne National Laboratory, August 1, 1956, pp.31-32 (ANL-5602). 
PRESSURE DEPENDENCE OF THE REACTION OF FLUORINE WITH NICKEL

For the reaction

$$
\mathrm{Ni}+\mathrm{F}_{2} \rightarrow \mathrm{NiF}_{2}
$$

the following rate equation is applicable.

$$
\frac{d x}{d t}=k c_{F_{2}}^{m} c_{N i}^{n}
$$

where $\frac{d x}{d t}=$ the rate of fluoride film formation which is proportional

$k=$ the specific reaction rate constant,

$\mathrm{C}_{\mathrm{F}_{2}}=$ concentration of fluorine,

$\mathrm{C}_{\mathrm{NI}}=$ concentration of nickel fonsidered to be constant at a given temperature since the total nickel fluoride film laid down during a series of measurements at a given temperature is quite small compared to the total nickel fluoride film aiready present) $m$ and $n$ are the orders of the reaction with respect to $\mathrm{C}_{\mathrm{F}_{2}}$ and
$\mathrm{C}_{\mathrm{Ni}}$, respectively.

Since $C_{N 1}^{n}$ remains practically constant during a series of measurements, $\mathrm{C}_{\mathrm{Ni}}^{\mathrm{n}}$ can be combined with $\mathrm{k}$ in a new constant $\mathrm{k}^{\mathrm{i}}$, then

$$
\frac{d x}{d t}=k^{s} \quad c_{F_{2}}^{m}
$$

or

$$
\frac{\mathrm{dx}}{\mathrm{dt}}=\mathrm{k}^{\prime \prime} \mathrm{P}_{\mathrm{F}_{2}}^{\mathrm{m}}
$$

where $P_{F_{2}}=$ fluorine pressure since $C_{F_{2}}^{m}=k^{m} P_{F_{2}}^{m}$

Thus,

$$
\log \left(\frac{d x}{d t}\right)=\log k^{n}+m \log P_{F_{2}}
$$

or a plot of the logarithm of the rate of nickel fluoride formation or the logarithm of fluorine consumption rate versus $\log \mathrm{P}_{F_{2}}$ gives a

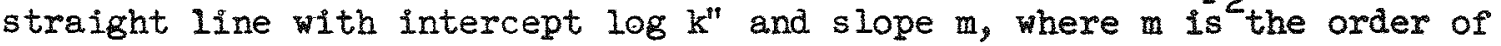
the reaction with respect to fluorine pressure or concentration. 